NASA/TM-2017-219558

\title{
Relationship Between Unusual High-Temperature Fatigue Crack Growth Threshold Behavior in Superalloys and Sudden Failure Mode Transitions
}

Jack Telesman, Timothy M. Smith, Timothy P. Gabb, and Andrew J. Ring Glenn Research Center, Cleveland, Ohio 


\section{NASA STI Program . . . in Profile}

Since its founding, NASA has been dedicated to the advancement of aeronautics and space science. The NASA Scientific and Technical Information (STI) Program plays a key part in helping NASA maintain this important role.

The NASA STI Program operates under the auspices of the Agency Chief Information Officer. It collects, organizes, provides for archiving, and disseminates NASA's STI. The NASA STI Program provides access to the NASA Technical Report Server-Registered (NTRS Reg) and NASA Technical Report ServerPublic (NTRS) thus providing one of the largest collections of aeronautical and space science STI in the world. Results are published in both non-NASA channels and by NASA in the NASA STI Report Series, which includes the following report types:

- TECHNICAL PUBLICATION. Reports of completed research or a major significant phase of research that present the results of NASA programs and include extensive data or theoretical analysis. Includes compilations of significant scientific and technical data and information deemed to be of continuing reference value. NASA counter-part of peer-reviewed formal professional papers, but has less stringent limitations on manuscript length and extent of graphic presentations.

- TECHNICAL MEMORANDUM. Scientific and technical findings that are preliminary or of specialized interest, e.g., "quick-release” reports, working papers, and bibliographies that contain minimal annotation. Does not contain extensive analysis.
- CONTRACTOR REPORT. Scientific and technical findings by NASA-sponsored contractors and grantees.

- CONFERENCE PUBLICATION. Collected papers from scientific and technical conferences, symposia, seminars, or other meetings sponsored or co-sponsored by NASA.

- SPECIAL PUBLICATION. Scientific, technical, or historical information from NASA programs, projects, and missions, often concerned with subjects having substantial public interest.

- TECHNICAL TRANSLATION. Englishlanguage translations of foreign scientific and technical material pertinent to NASA's mission.

For more information about the NASA STI program, see the following:

- Access the NASA STI program home page at http://www.sti.nasa.gov

- E-mail your question to help@sti.nasa.gov

- Fax your question to the NASA STI Information Desk at 757-864-6500

- Telephone the NASA STI Information Desk at 757-864-9658

- Write to:

NASA STI Program

Mail Stop 148

NASA Langley Research Center Hampton, VA 23681-2199 
NASA/TM-2017-219558

\section{Relationship Between Unusual High-Temperature Fatigue Crack Growth Threshold Behavior in Superalloys and Sudden Failure Mode Transitions}

Jack Telesman, Timothy M. Smith, Timothy P. Gabb, and Andrew J. Ring Glenn Research Center, Cleveland, Ohio

National Aeronautics and

Space Administration

Glenn Research Center

Cleveland, Ohio 44135 


\section{Acknowledgments}

This authors would like to gratefully acknowledge helpful discussions with Dr. Kwai Chan of the Southwest Research Institute. This work supports the objectives and goals of NASA's Advanced Air Transportation Technology Project funded by the Aeronautics Research Mission Directorate.

This work was sponsored by the Advanced Air Vehicle Program at the NASA Glenn Research Center

Level of Review: This material has been technically reviewed by technical management.

Available from

NASA STI Program

Mail Stop 148

NASA Langley Research Center

Hampton, VA 23681-2199
National Technical Information Service 5285 Port Royal Road Springfield, VA 22161 703-605-6000

This report is available in electronic form at http://www.sti.nasa.gov/ and http://ntrs.nasa.gov/ 


\title{
Relationship Between Unusual High-Temperature Fatigue Crack Growth Threshold Behavior in Superalloys and Sudden Failure Mode Transitions
}

\author{
Jack Telesman, Timothy M. Smith, Timothy P. Gabb, and Andrew J. Ring \\ National Aeronautics and Space Administration \\ Glenn Research Center \\ Cleveland, Ohio 44135
}

\begin{abstract}
An investigation of high temperature cyclic fatigue crack growth (FCG) threshold behavior of two advanced nickel disk alloys was conducted. The focus of the study was the unusual crossover effect in the near-threshold region of these type of alloys where conditions which produce higher crack growth rates in the Paris regime, produce higher resistance to crack growth in the near threshold regime. It was shown that this crossover effect is associated with a sudden change in the fatigue failure mode from a predominant transgranular mode in the Paris regime to fully intergranular mode in the threshold fatigue crack growth region. This type of a sudden change in the fracture mechanisms has not been previously reported and is surprising considering that intergranular failure is typically associated with faster crack growth rates and not the slow FCG rates of the near-threshold regime. By characterizing this behavior as a function of test temperature, environment and cyclic frequency, it was determined that both the crossover effect and the onset of intergranular failure are caused by environmentally driven mechanisms which have not as yet been fully identified. A plausible explanation for the observed behavior is proposed.
\end{abstract}

\section{Introduction}

The use of damage tolerance methodology to meet engine certification requirements of nickel-based turbine rotating components requires extensive characterization and thorough understanding of the fatigue crack growth processes of turbine disk alloys. Of particular importance for achieving accurate damage tolerance life predictions is the threshold fatigue crack growth behavior under both cyclic and hold time conditions which consumes the bulk of the crack growth lives. While extensive work has been published in the literature over the years in regards to the high temperature FCG behavior of nickel-based superalloys in the Paris regime (i.e., at the intermediate and higher crack growth rates), relatively little research has appeared in publications on the near-threshold FCG behavior. However, the studies which have been published suggest that the high temperature cyclic FCG near-threshold behavior of superalloys may differ considerably from that observed in other classes of alloys (Refs. 1 to 6).

It is well established that nickel-based superalloy mechanical properties are sensitive to environmental degradation as temperatures are increased, especially for test temperatures exceeding $538^{\circ} \mathrm{C}\left(1000^{\circ} \mathrm{F}\right)$ (Ref. 7). In terms of cyclic FCG behavior, an increase in temperature results in substantial increase in FCG rates. For instance, ME3 turbine disk alloy exhibits over an order of magnitude faster cyclic FCG rates at $704{ }^{\circ} \mathrm{C}$ in comparison to $204{ }^{\circ} \mathrm{C}$ (Ref. 8). The sensitivity of dwell FCG (DFCG) behavior to temperature is even more pronounced, with a number of disk alloys exhibiting a 10 times increase in crack growth rates for every $56^{\circ} \mathrm{C}\left(100^{\circ} \mathrm{F}\right)$ increase in test temperature at temperatures exceeding $594{ }^{\circ} \mathrm{C}\left(1100^{\circ} \mathrm{F}\right)$ (Ref. 9).

The unusual high temperature superalloy FCG near-threshold behavior can be ascertained from data published on Alloy 718 (Ref. 1), Astroloy (Ref. 2), KM4 (Refs. 3 and 4), and Alloy 720Li (Ref. 5). In most classes of metal alloys, higher Paris regime FCG rates are typically associated with either lower or similar threshold FCG stress intensities (Refs. 10 to 12). This is especially evident when FCG rates are plotted in terms of the applied minimum/maximum stress ratio $(\mathrm{R})$ where the higher stress ratios produce 
considerably higher Paris regime FCG rates and lower thresholds (Ref. 13). However, the work on Alloy 718 (Ref. 1) and Astroloy (Ref. 2) demonstrated that while an increase in the test temperature significantly increased the Paris regime cyclic FCG rates, a crossover occurs in the near-threshold regime resulting in considerably higher FCG threshold stress intensities, $\Delta \mathrm{K}_{\text {th }}$, occurring at temperatures where environmental degradation is also known to occur. Yuen et al. (Ref. 1) ascribed this effect in Alloy 718 to oxide induced crack closure significantly reducing the effective crack driving force, $\Delta \mathrm{K}_{\text {eff. }}$ They postulated that oxide kinetics were important in increasing the oxide thickness at elevated temperatures to levels which affected the crack driving force. However, the crossover effect persisted even at high $\mathrm{R}$ ratios where the influence of oxide induced closure should have been significantly diminished. Shaym et al. (Ref. 3) found that for KM4 disk alloy tested, not only test temperature but also test frequency has an effect on cyclic FCG thresholds, with lower frequencies increasing the threshold stress intensities. In a recent study of Alloy 720Li, Li and co-workers (Ref. 5) demonstrated that thresholds for dwell FCG where intergranular failure mode is dominant, are higher than for cyclic FCG tests even though the crack growth rates in the Paris regime are an order of magnitude higher for the DFCG tests. They postulated that crack tip blunting, which occurs during prolong dwells, reduces the crack driving force which in turn is responsible for the higher threshold stress intensities.

Due to the importance of the near-threshold FCG behavior on life prediction as well as the lack of clear understanding of the mechanisms causing the unusual threshold behavior in superalloys, the current study re-examines this issue by focusing on the effect of temperature, frequency and the environment on near-threshold FCG behavior of two nickel-based powder metallurgy (P/M) disk alloys, ME3 and LSHR. Particular attention in the study has been paid to the governing failure modes and their relationship to the near-threshold FCG behavior.

\section{Experimental}

\section{Materials and Heat Treatment}

Blanks of forged LSHR and pancake forgings of ME3 disk alloys of compositions shown in Table 1, were heat treated and given a two-step aging treatment. LSHR blanks were solutioned for $2 \mathrm{hr}$ at $1171{ }^{\circ} \mathrm{C}$ and aged at $855^{\circ} \mathrm{C} / 4 \mathrm{~h}$ and $775^{\circ} \mathrm{C} / 8 \mathrm{~h}$ to achieve a supersolvus microstructure with an average grain size of approximately ASTM 8. ME3 forgings were solutioned at $1171{ }^{\circ} \mathrm{C}$ for $2 \mathrm{hr}$ and aged at $843{ }^{\circ} \mathrm{C} / 4 \mathrm{~h}$ and $760^{\circ} \mathrm{C} / 8 \mathrm{~h}$ to achieve a supersolvus microstructure with an average grain size of approximately ASTM 7 . Typical resulting microstructures are shown in Figure 1.

TABLE 1.-AVERAGE ALLOY COMPOSITION IN WEIGHT PERCENT

\begin{tabular}{|c|c|c|c|c|c|c|c|c|c|c|c|c|}
\hline Alloy & $\mathrm{Cr}$ & $\mathrm{Co}$ & $\mathrm{Al}$ & $\mathrm{Ti}$ & $\mathrm{Nb}$ & $\mathrm{Mo}$ & $\mathrm{Ta}$ & $\mathrm{W}$ & $\mathrm{Zr}$ & $\mathrm{B}$ & $\mathrm{C}$ & $\mathrm{Ni}$ \\
\hline LSHR & 12.5 & 20.4 & 3.5 & 3.5 & 1.5 & 2.7 & 1.5 & 4.3 & 0.05 & 0.03 & 0.045 & $\mathrm{Bal}$ \\
\hline ME3 & 13 & 21 & 3.4 & 3.8 & 0.8 & 3.7 & 2.4 & 2.1 & 0.05 & 0.02 & 0.05 & $\mathrm{Bal}$ \\
\hline
\end{tabular}
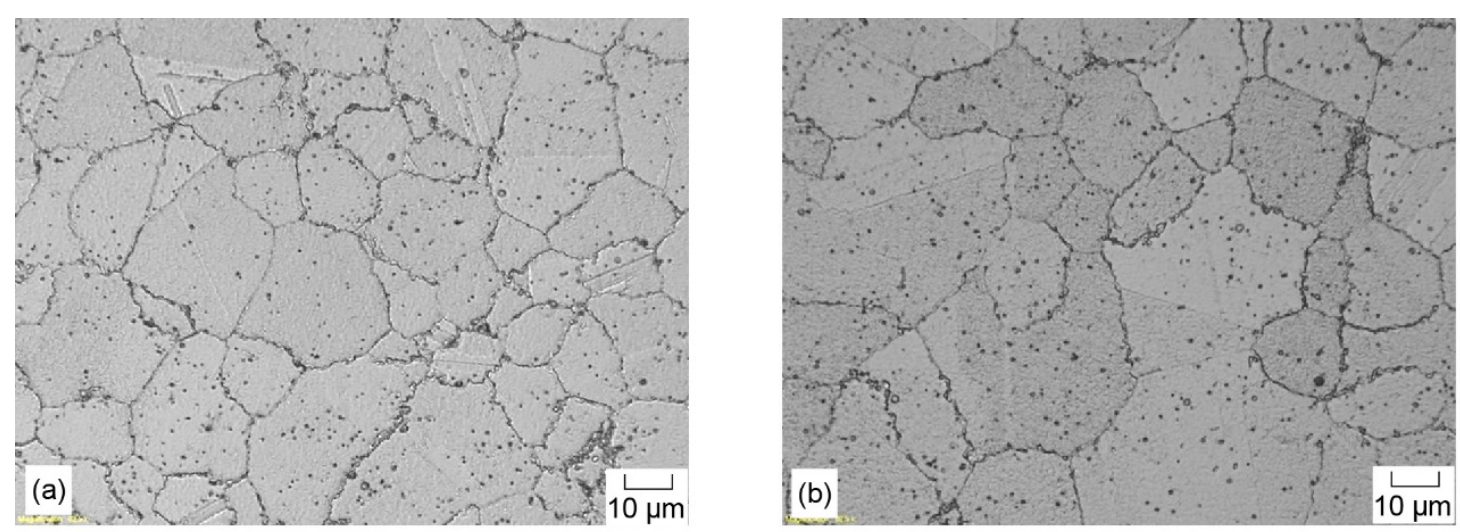

Figure 1.-Optical micrographs of (a) LSHR and (b) ME3 alloys. 


\section{Fatigue Crack Growth Testing}

All crack growth testing was performed using the surface flaw, $\mathrm{Kb}$ bar specimen geometry with crack lengths measured by a computerized direct current electrical potential (DCEP) drop system. All specimens were pre-cracked at room temperature. Most of the testing was performed at $704{ }^{\circ} \mathrm{C}$ in air with selected testing also done at 538 and $760{ }^{\circ} \mathrm{C}$. To determine the effect of the environment, a small subset of tests was performed in a vacuum chamber at a $10^{-7}$ Torr pressure range. After room temperature pre-cracking, threshold testing was performed with the approximate initial stress intensity range $(\Delta K)$ of $24 \mathrm{MPa} \sqrt{\mathrm{m}}$. Due to the geometry limitations imposed by the use of $\mathrm{Kb}$ bar specimens, a steep stress intensity shedding rate, $\mathrm{C}=-0.8 \mathrm{~mm}^{-1}$, was utilized for the threshold tests. For some of the specimens, once near-threshold FCG rates were achieved, the stress intensity was increased and the test was continued under an applied constant stress range. In order to obtain near-threshold FCG data without the use of a steep load shedding procedure, selected tests were pre-cracked to shorter crack lengths and the near-threshold data was acquired by conducting the test under constant stress range conditions which produced the more typical $\Delta \mathrm{K}$ increasing FCG curves.

\section{Results}

\section{Load Shedding Threshold FCG Testing}

The load shedding threshold FCG results for tests conducted in air at 538, 704, and $760{ }^{\circ} \mathrm{C}$ for the ME3 alloy are shown in Figure 2. The ME3 alloy exhibits the same FCG trends previously reported for Alloy 718 and Astroloy (Refs. 1 and 2). Thus in the Paris regime, the FCG rates increase as the temperatures rise, however in the threshold regime a crossover occurs resulting in an increase in the threshold stress intensity, $\Delta \mathrm{K}_{\text {th }}$, with an increase in test temperature. At $538^{\circ} \mathrm{C}$, the $\Delta \mathrm{K}_{\text {th }}$ is approximately 8.2 $\mathrm{MPa} \sqrt{\mathrm{m}}, 11.4 \mathrm{MPa} \sqrt{\mathrm{m}}$ at $704{ }^{\circ} \mathrm{C}$ and $14 \mathrm{MPa} \sqrt{\mathrm{m}}$ at $760{ }^{\circ} \mathrm{C}$. The $704{ }^{\circ} \mathrm{C}$ load shedding threshold FCG results for the LSHR alloy are shown in Figure 3. Here the major variable is the test environment with multiple tests conducted in air compared to a vacuum threshold test. As shown, the FCG rates in the

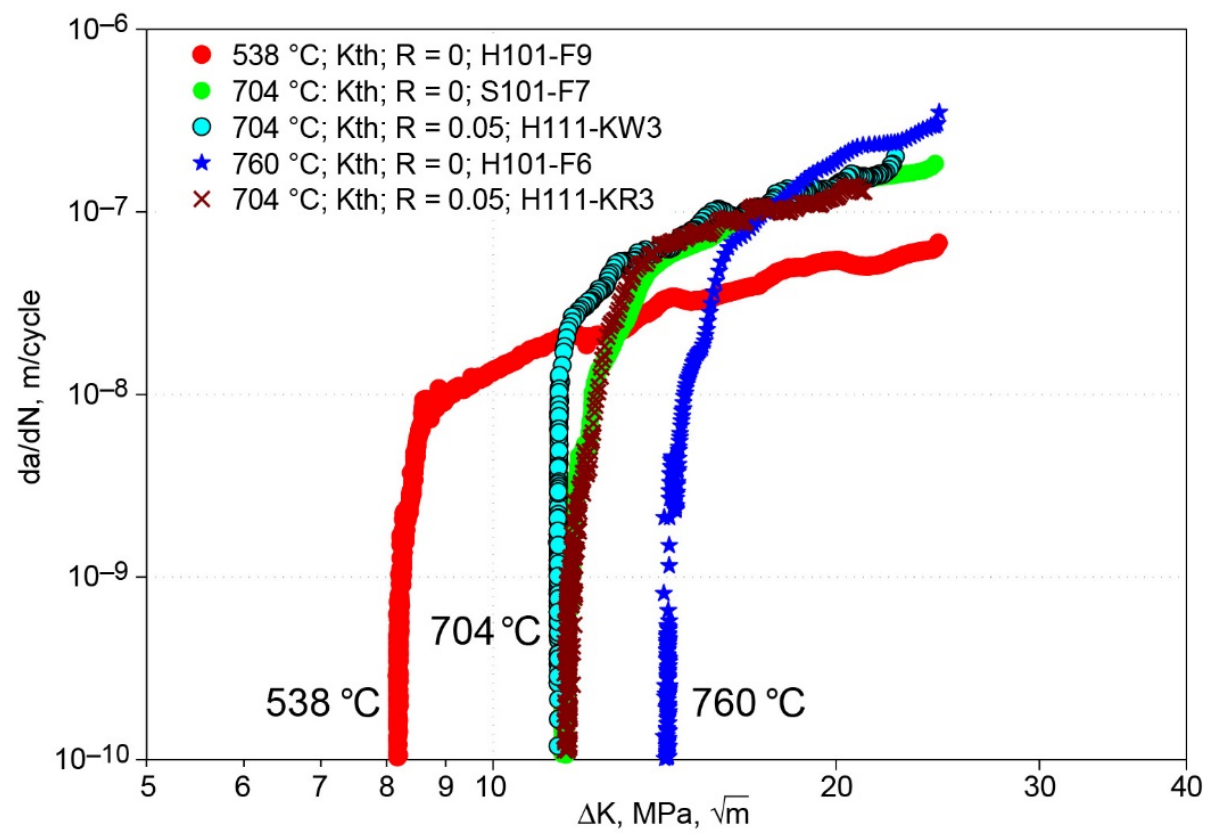

Figure 2.- Load shedding FCG test results for ME3 tested in air at 538, 704 , and $760{ }^{\circ} \mathrm{C}$. 
Paris regime for the test conducted in vacuum were approximately three times slower in comparison to the similar tests conducted in air. The crossover effect is again evident with the vacuum test exhibiting faster near-threshold FCG rates and lower apparent $\Delta \mathrm{K}_{\text {th }}$ than the tests conducted in air. Effect of frequency was evaluated by performing a $704{ }^{\circ} \mathrm{C}$ air threshold test on LSHR specimen at $20 \mathrm{~Hz}$. As shown in Figure 4, the Paris regime FCG rates at $20 \mathrm{~Hz}$ were somewhat lower than for the $0.333 \mathrm{~Hz}$, however the $\Delta \mathrm{K}_{\mathrm{th}}$ was much lower in comparison to the slower frequency thus again exhibiting the crossover effect. The threshold stress intensities, defined as the $\Delta \mathrm{K}$ levels at the $1 \times 10^{-10} \mathrm{~m} / \mathrm{cycle}$ crack growth rate, were approximately 25 to 30 percent higher at $0.333 \mathrm{~Hz}$ than for the test performed at $20 \mathrm{~Hz}$.

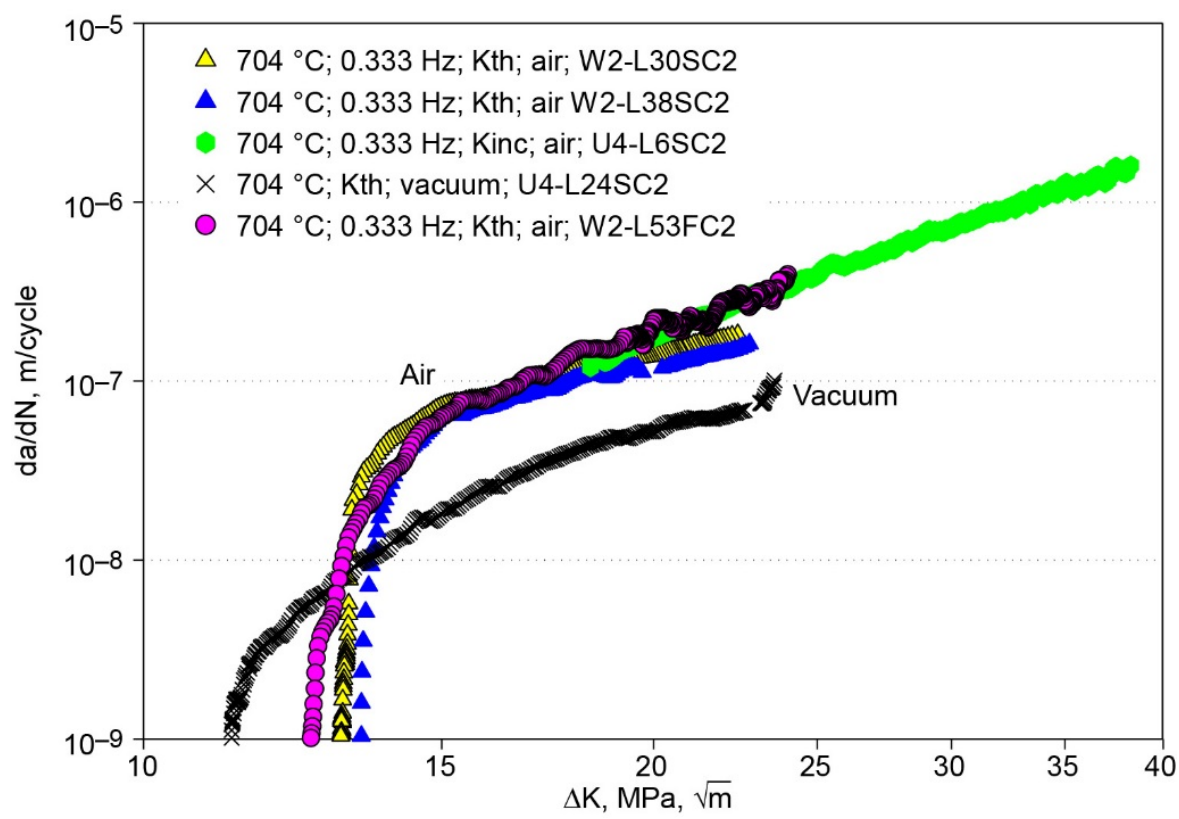

Figure 3.-LSHR FCG load shedding test results in air and vacuum at $704^{\circ} \mathrm{C}$ at $0.333 \mathrm{~Hz}$.

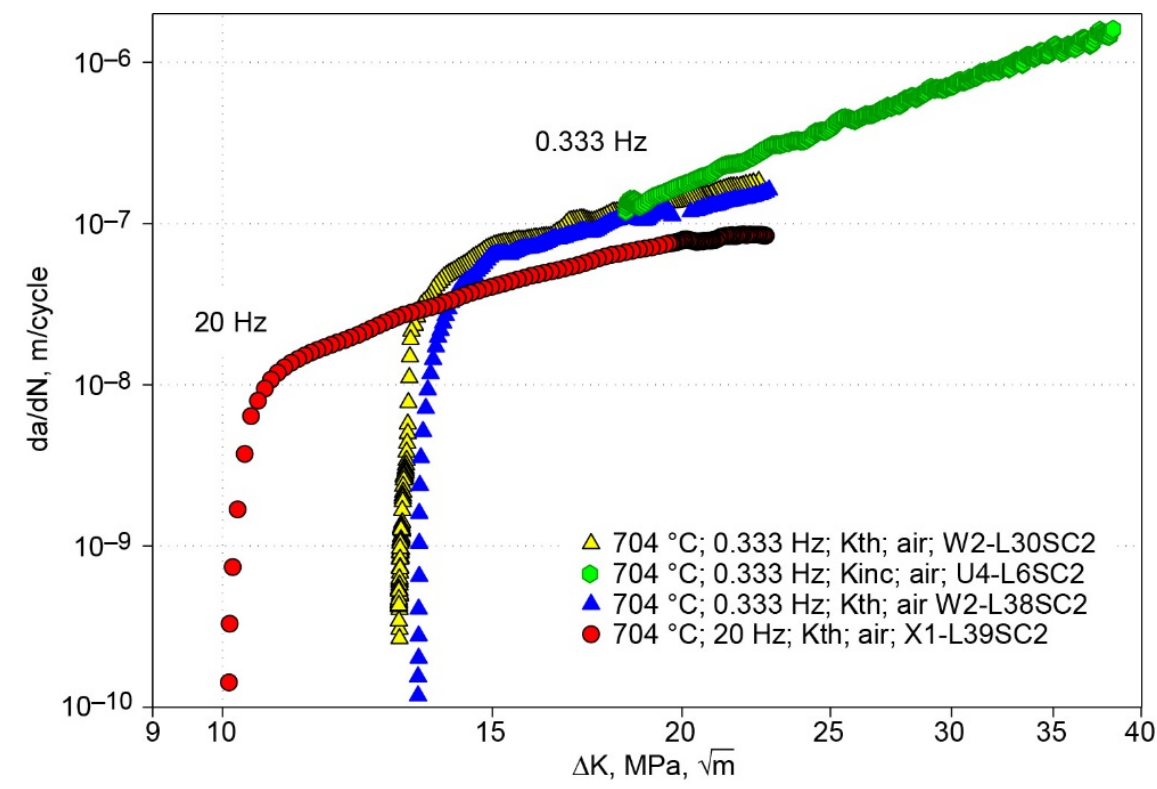

Figure 4.-LSHR $704{ }^{\circ} \mathrm{C}$ test conducted at $20 \mathrm{~Hz}$ shows a crossover effect in comparison to tests performed at $0.333 \mathrm{~Hz}$. 
The unusual near-threshold FCG behavior of tests performed on both ME3 and LSHR test coupons may be indicative of the role that environment can have on the fatigue crack growth behavior of superalloys. Since higher temperatures increase the rate of environmentally embrittling crack tip reactions, the faster FCG rates in the Paris regime at higher temperatures are not at all surprising. However, the differences in the near-threshold FCG behavior between vacuum and air at the same temperature suggest that another environment-based damage mechanism may be also in play. The effect of frequency is also consistent with this rationale since much higher cyclic frequencies limit the amount of time available for the environmentally driven reactions to take place. Detailed damage mode microstructural evaluation was performed in an attempt to characterize and identify this mechanism.

\section{Failure Mode Transitions}

Fractographic and metallographic examination of the threshold FCG specimens was conducted to characterize the active fatigue crack growth failure mechanisms. For the testing conducted in air at $704{ }^{\circ} \mathrm{C}$ at $0.333 \mathrm{~Hz}$, fractographic examination revealed a sudden transformation of the damage mechanisms between the Paris region and the near-threshold fatigue crack growth regime. As shown in Figure 5 and Figure 6 for LSHR and in Figure 7 and Figure 8 for ME3, the failure mode abruptly changes from a mixed mode (i.e., mixture of mostly transgranular with some intergranular regions) to fully intergranular. What is especially striking is that the mixed failure mode is associated with the faster FCG rates of the Paris regime while the fully intergranular failure mode occurs at the onset of transition to much slower near-threshold FCG regime and continues throughout the crack growth in the threshold region. This is in contrast to the usual trends observed during crack growth in superalloys where the intergranular failure mode is associated with much faster crack propagation rates than transgranular failure mode (Refs. 5 and 9). Based on the literature survey conducted, the existence of such failure mode transition in the near-threshold regime has not been previously reported.

As shown in the optical images of two threshold tests at $704{ }^{\circ} \mathrm{C}$, for both LSHR, Figure 5(a), and ME3, Figure 7(a), the intergranular threshold region is manifested by a thin dark ring encircling the Paris regime crack growth region. Also visible are the room temperature (RT) pre-cracking region, and the final room temperature crack growth region. Higher magnification scanning electron microscopy (SEM) images of the intergranular failure (Figure 6 and Figure 8) reveal the region to be almost continuous with its width ranging approximately from 20 to $150 \mu \mathrm{m}$ and spanning 1 to 6 grains. The width of the intergranular region for all these specimens corresponds very closely to the crack lengths increments from
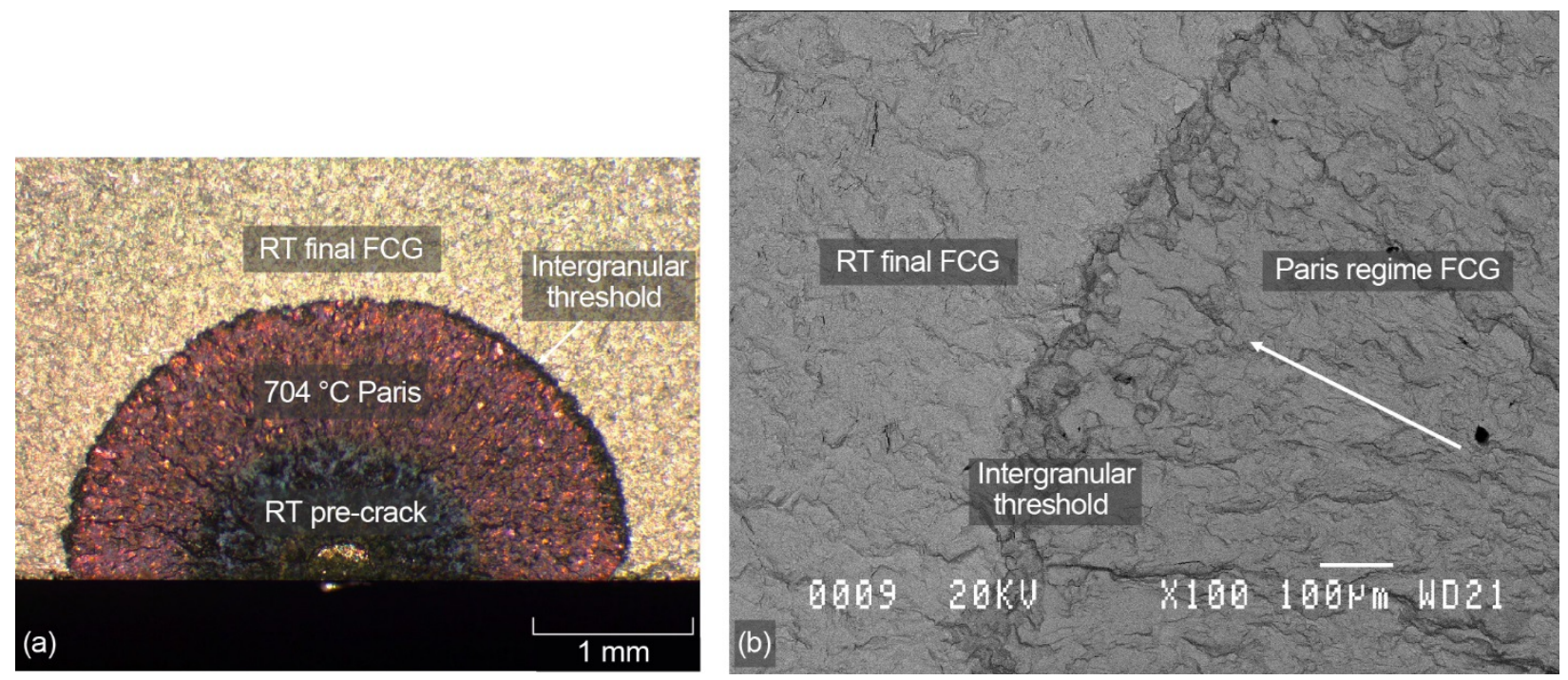

Figure 5.-Optical (a) and back scatter SEM (b) images of a LSHR load shed threshold test fracture surface. The thin, darker ring on both images was caused by the change of reflection/emissions due to intergranular failure. 

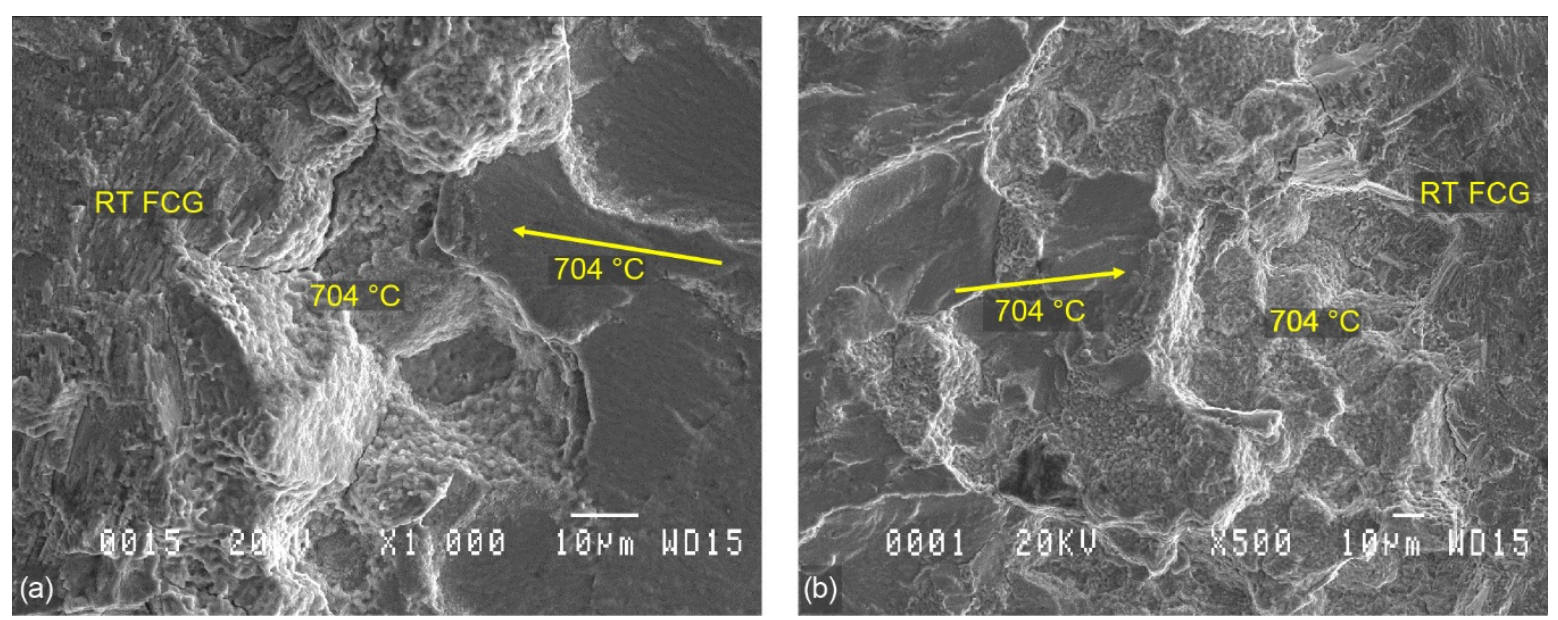

Figure 6.-Higher magnification images of sudden failure mode transition during load shedding of LSHR FCG threshold tests at $704{ }^{\circ} \mathrm{C}$ and $0.333 \mathrm{~Hz}$ : (a) failure mode transition, (b) failure mode transition-opposite side of the same specimen. Arrows indicate crack growth direction.
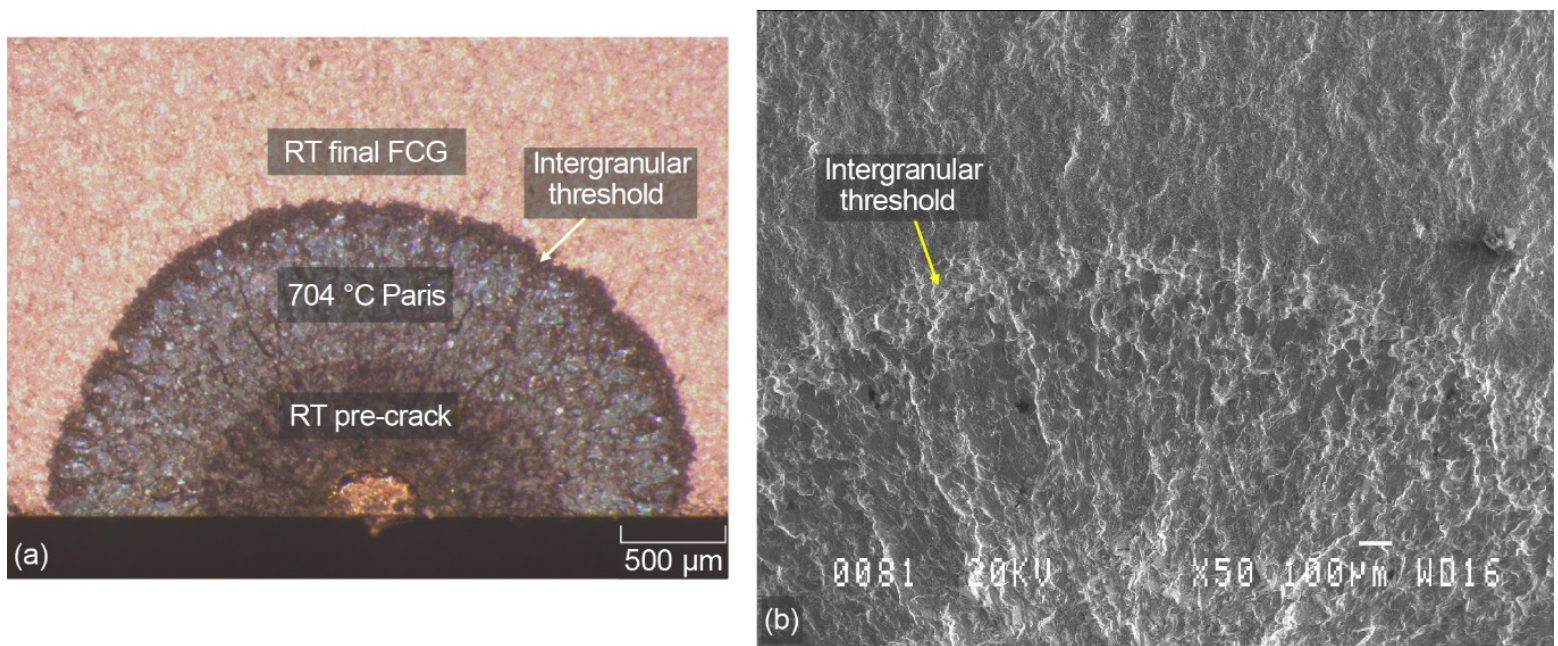

Figure 7.-(a) Optical and (b) SEM images of a ME3 $704{ }^{\circ} \mathrm{C}$ load shedding threshold specimen tested at $704{ }^{\circ} \mathrm{C}$ and $0.333 \mathrm{~Hz}$. Intergranular region is present near-threshold.
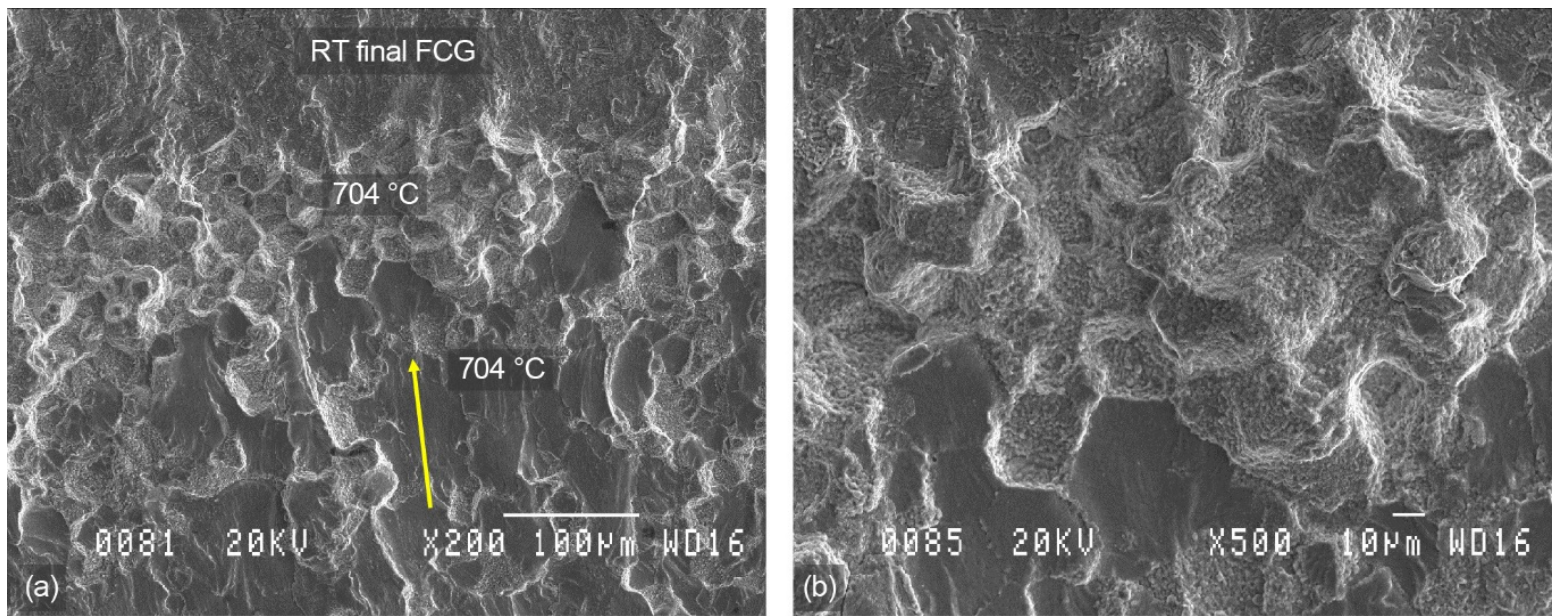

Figure 8.-Sudden transition in failure mode in the near-threshold regime for ME3-for a load shed threshold test conducted at $704{ }^{\circ} \mathrm{C}$ and $0.333 \mathrm{~Hz}$ : (a) failure mode transition region, (b) higher magnification image showing local variations in region width. 
the onset of the near-threshold regime, taken to be the change of slope away from the Paris region (approximately $4 \times 10^{-8} \mathrm{~m} /$ cycle) to the end of the threshold test as is detailed in Table 2 . In addition to the load shedding test comparison, the table also shows the comparison for the $\mathrm{K}$ increasing/short pre-crack tests which will be discussed in more detail later on. As shown, there is some variability in width for these measurements of the intergranular band depending on test type and alloy tested. However, in all cases there is a good agreement between the SEM measurements and the width of the near-threshold FCG regime thus confirming the relationship between the failure mode change and the onset of the unusual FCG behavior. Additional tests would be necessary to determine if there is a consistent dependence of width on test type, grain size, or alloy.

Supersolvus grain boundaries of disk alloys are normally decorated by $\gamma^{\prime}$ precipitates which grow preferentially larger there to produce a bumpy appearance. Due to an extensive time spent at high temperature during the slow near threshold crack growth, a thin oxide film on top of the intergranular grain boundary precipitate structure has developed as observed in the high magnification images in Figure 9. More detailed characterization of the oxide films and their role on the near-threshold FCG behavior will be discussed later on in the manuscript.

The existence of the failure mode transition in the near-threshold regime is dependent on the test environment, test temperature and test frequency. As shown in Figure 10, the ME3 FCG threshold test conducted in air at $538^{\circ} \mathrm{C}$ did not undergo the sudden transition in failure modes. The failure mode was in both the Paris regime and in the near-threshold regions almost exclusively transgranular with small,

TABLE 2.-COMPARISON OF INTERGRANULAR BAND WIDTH WITH NEAR-THRESHOLD REGION CRACK GROWTH DISTANCE-704 ${ }^{\circ} \mathrm{C}$

\begin{tabular}{|l|l|c|c|c|}
\hline \multicolumn{1}{|c|}{ Alloy/Specimen } & \multicolumn{1}{|c|}{ Test type } & $\begin{array}{c}\text { Frequency, } \\
(\mathrm{Hz})\end{array}$ & $\begin{array}{c}\text { Crack length distance to/from } \\
4 \times 10^{-8} \mathrm{~m} / \mathrm{cycle} \text { to/from threshold, } \\
(\mu \mathrm{m})\end{array}$ & $\begin{array}{c}\text { Avg. intergranular band width, } \\
(5 \mathrm{measurements} \mathrm{-} \mu \mathrm{m})\end{array}$ \\
\hline LSHR W2-L30SC2 & Load shedding & 0.333 & 75 & 72 \\
\hline LSHR W2-L38SC2 & Load shedding & 0.333 & 75 & 82 \\
\hline LSHR W2-L53FC2 & Load shedding & 0.333 & 187 & 170 \\
\hline ME3 H111-KW3 & Load shedding & 0.333 & 110 & 110 \\
\hline ME3 H111-KR3 & Load shedding & 0.333 & 120 & 131 \\
\hline LSHR T2-K5 & Const load/short pre-crack & 2 & 205 & 222 \\
\hline LSHR T2-K6 & Const load/short pre-crack & 0.667 & & 137 \\
\hline
\end{tabular}
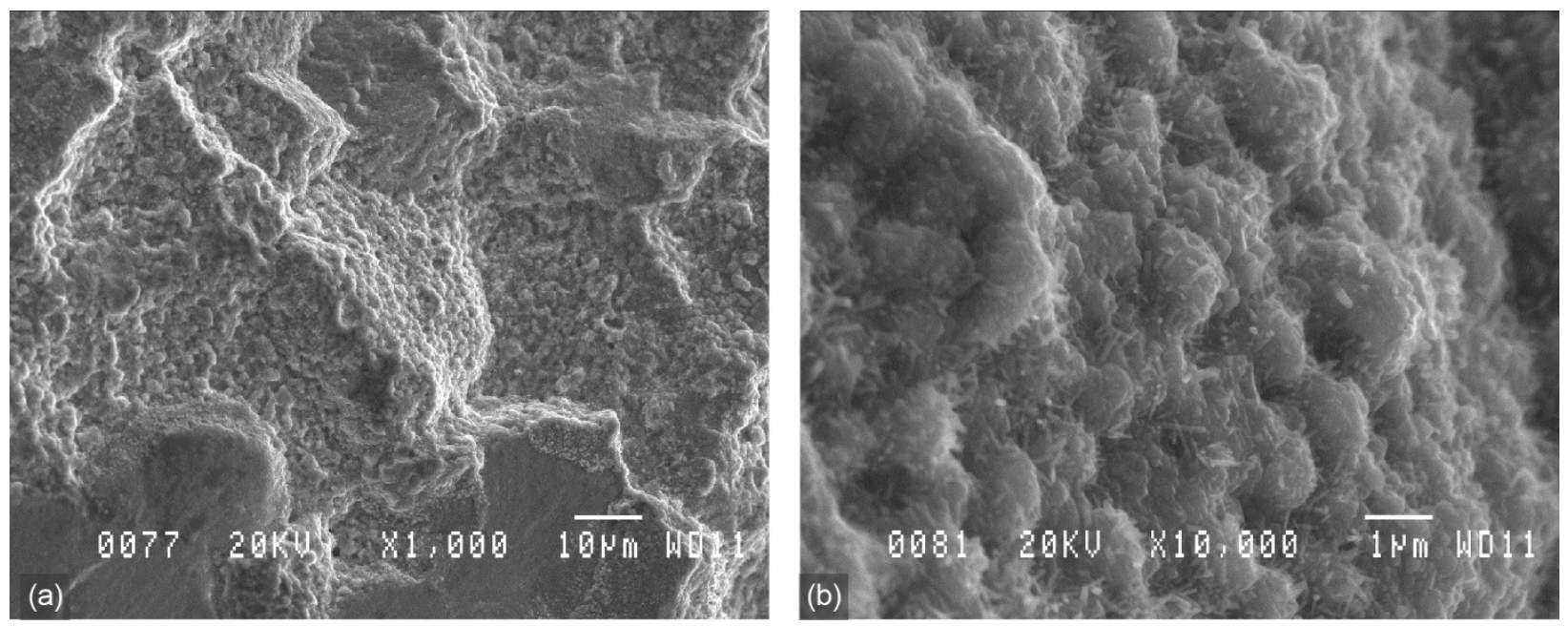

Figure 9.-ME3 load shed test specimen showing oxidation occurring on the $\gamma^{\prime}$ precipitates present at the grain boundaries: (a) bumpy appearance of exposed grain boundaries due to larger $\gamma^{\prime}$ precipitates at grain boundaries, (b) oxides on these $V^{\prime}$ precipitates. 
isolated regions of intergranular failure. For the LSHR FCG threshold test performed at $704{ }^{\circ} \mathrm{C}$ in vacuum at $0.333 \mathrm{~Hz}$, the failure mode was fully transgranular with no regions of intergranular failure detected, Figure 11(a) and (b). In case of the LSHR FCG test conducted in air at the same temperature, but at a much higher frequency of $20 \mathrm{~Hz}$, the failure mode was again mostly transgranular, however in the near-threshold region, isolated areas of intergranular failure were present (Figure 11(c) and (d)).
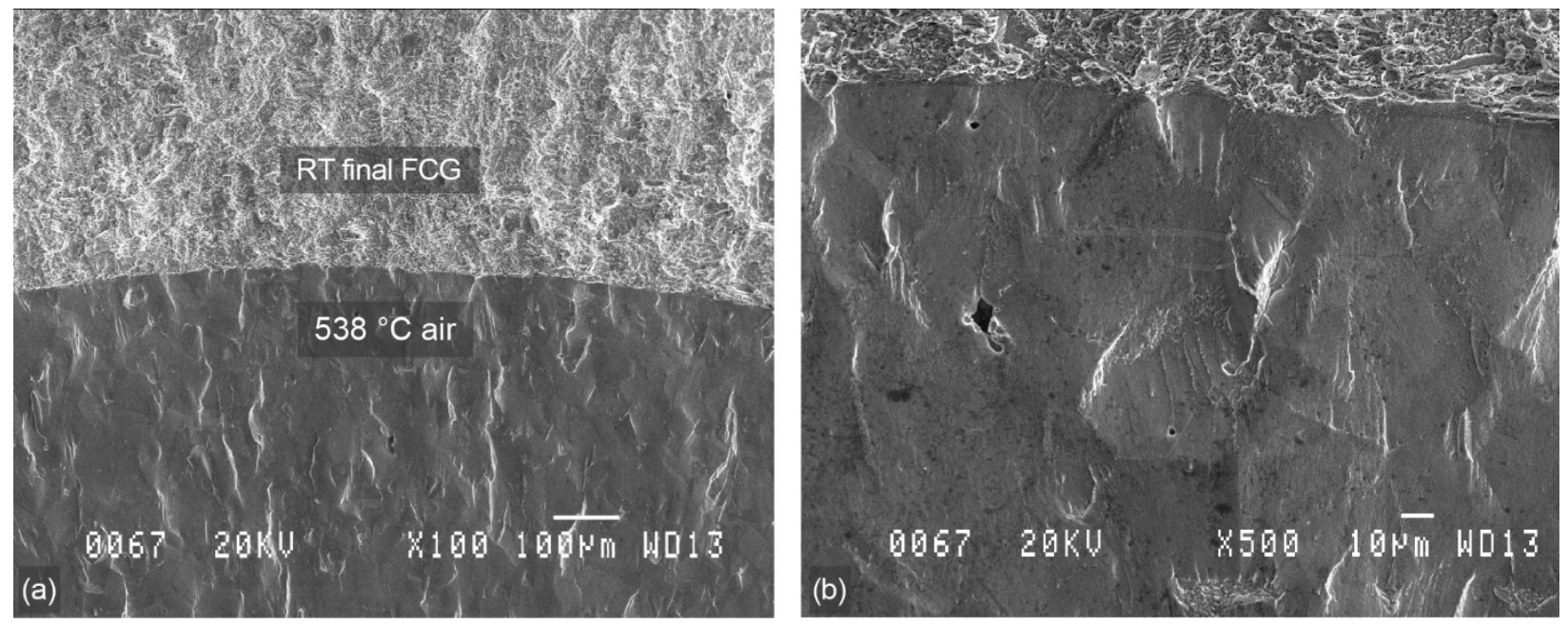

Figure 10.-ME3 load shedding FCG tested at $538^{\circ} \mathrm{C}$ in air. Mostly transgranular failure mode, throughout the test duration. Lower magnification in (a) and higher magnification in (b). No failure mode transition to intergranular cracking is observed.
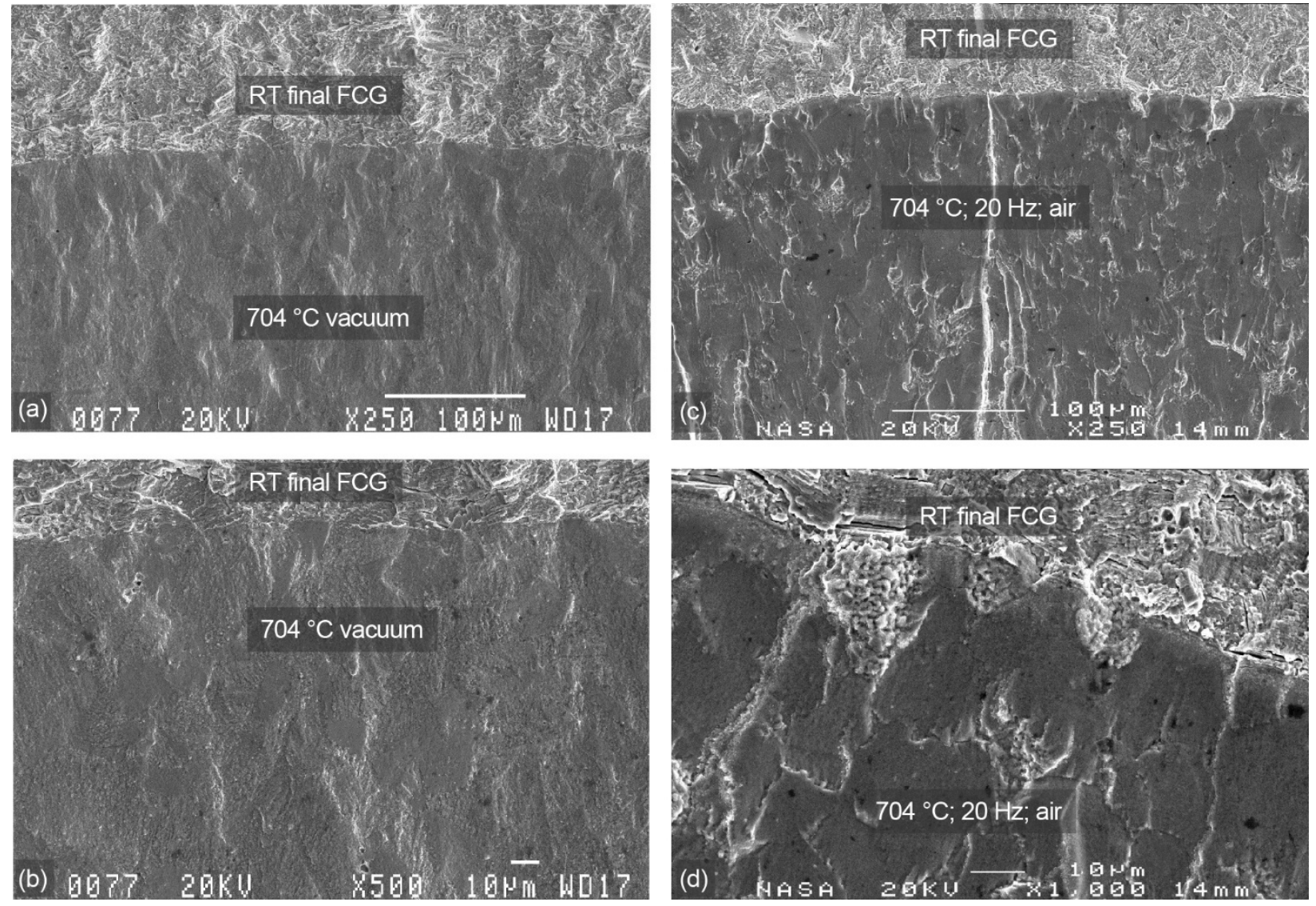

Figure 11.-LSHR load shedding FCG tests performed at $704{ }^{\circ} \mathrm{C}$ in vacuum, (a) and (b), or at $20 \mathrm{~Hz}$ in air, (c) and (d), did not show the sudden failure mode transition. 
All the ME3 and LSHR tests which exhibited mostly transgranular failure and did not exhibit a sudden change in the failure mode, resulted in considerably lower threshold stress intensities than their counterparts which did experience failure mode transition (Figure 2 to Figure 4). Since all the nontransition tests were performed at conditions which minimize the effect of environment, i.e., lower temperature, vacuum or high frequency, the results provide additional evidence that the observed sudden failure mode transition is due to an environmentally driven mechanism.

\section{$\Delta \mathrm{K}$ Increasing Fatigue Crack Growth Testing}

Further characterization of the near-threshold regime FCG behavior was performed by using two other test procedures. The bulk of the near-threshold FCG test results was obtained through an aggressive load shedding procedure in which the shedding rate was considerably greater than recommended by the ASTM E-647 standard (Ref. 14). This was done so that FCG data could be obtained over a wider $\Delta \mathrm{K}$ range than it would have been possible with the recommended shedding rate. In order to confirm that the near-threshold FCG obtained data provided accurate results, additional testing was done by curtailing the crack length of the room temperature pre-crack procedure. After the abbreviated pre-cracking, constant load testing was initiated at near-threshold stress intensities. Thus the low $\Delta \mathrm{K} F C G$ data in these tests was generated without the load history effects and without first creating the intergranular near-threshold failure mode.

The results of these tests performed on LSHR specimens in air and vacuum are shown in Figure 12(a) while a comparison between the load shedding and short pre-crack tests tested in air is shown in Figure 12(b). As shown in Figure 12(b), the short pre-crack results are generally in good agreement with the load shedding results. The near-threshold FCG rates derived from the short pre-crack tests, while not identical, are similar to those obtained from the load shedding tests. Also in Paris regime the results between the two types of tests are also similar. It should be pointed out that the short pre-crack tests were run at somewhat higher frequencies $(0.667$ and $2 \mathrm{~Hz})$ than the $0.333 \mathrm{~Hz}$ used for load shedding tests.

The fractography of the short pre-crack tests is shown in Figure 13 and Figure 14. As shown, for both specimens, the fully intergranular near-threshold failure mode is initiated immediately at the start of the high temperature test. This is readily evident in the figures because of the contrast between the highly faceted, crystallographic room temperature fatigue failure mode and the intergranular near-threshold high temperature failure. The fully intergranular near-threshold failure mode grew over a distance of approximately 120 to $225 \mu \mathrm{m}$ (Table 2) and then suddenly transitioned to the more typical mixed mode fatigue crack growth failure mode as shown in Figure 13(b) and Figure 14(b).
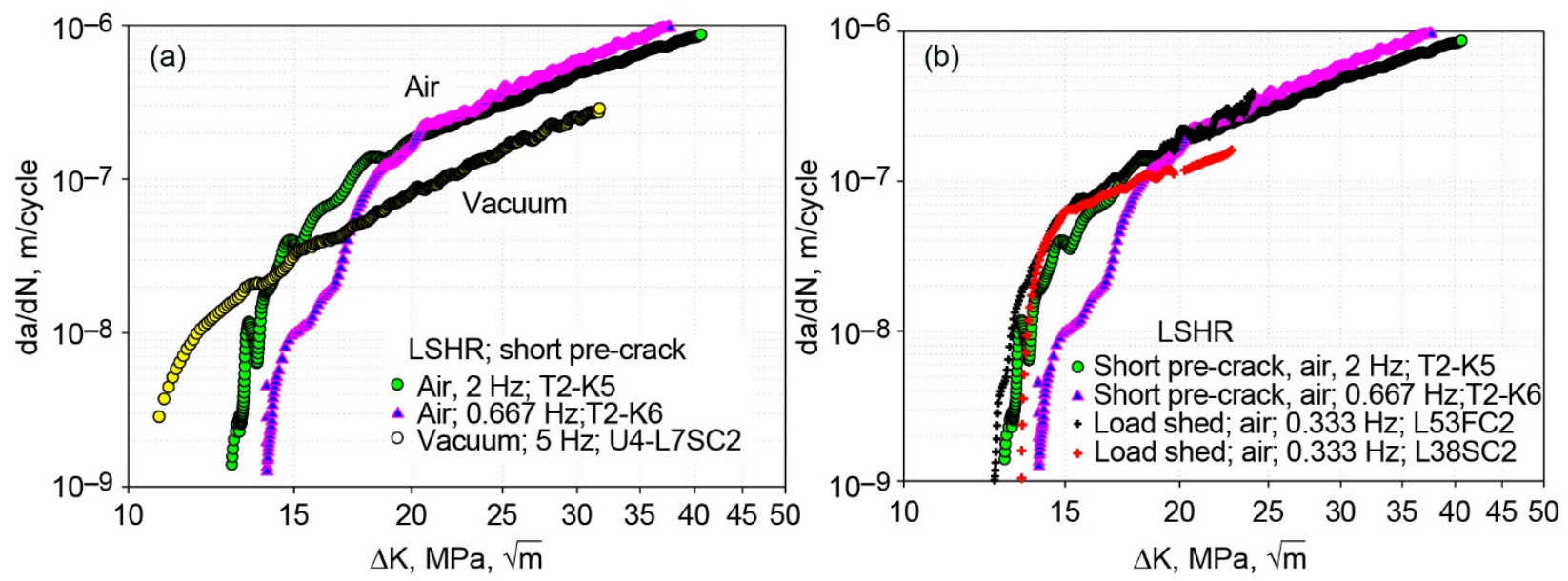

Figure 12.-Near-threshold, short pre-crack FCG tests performed on LSHR at $704^{\circ} \mathrm{C}$ : (a) in air and vacuum,

(b) comparison between load shedding and short pre-crack FCG results. 

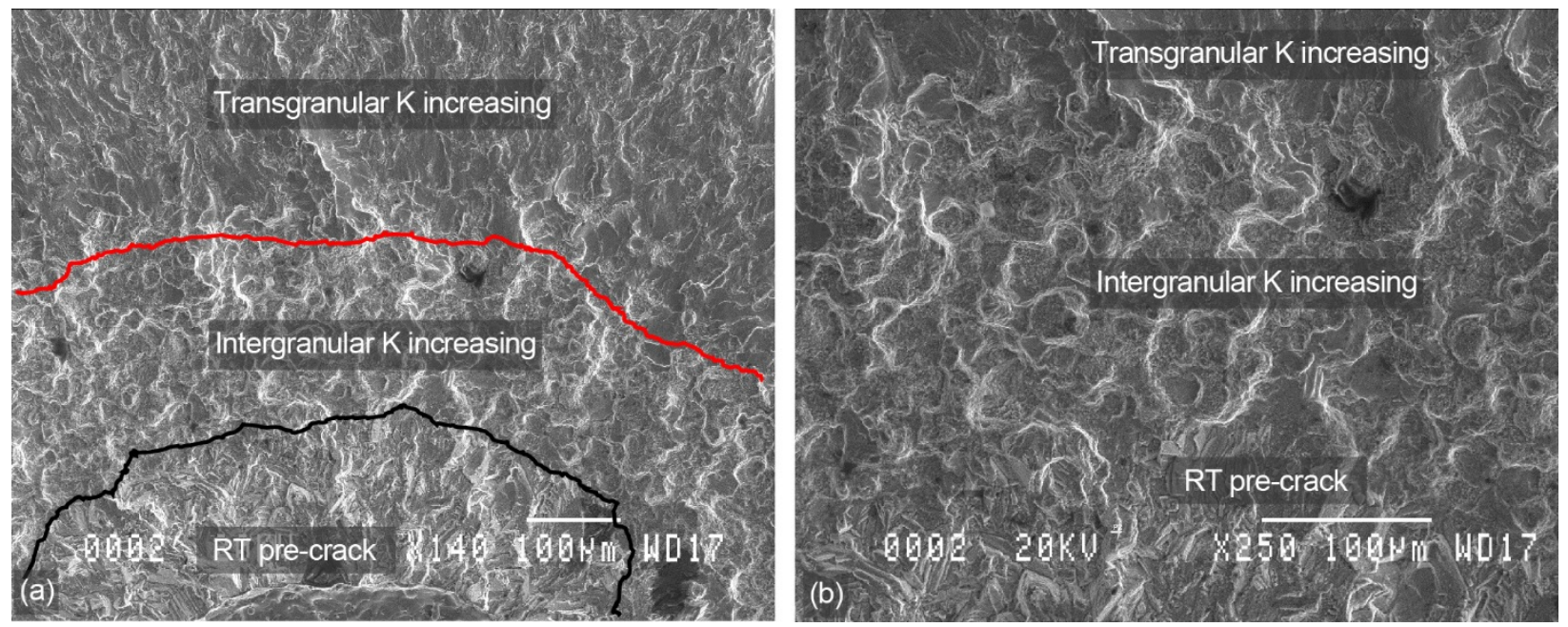

Figure 13._LSHR short pre-crack, $\mathrm{K}$ increasing ( $\mathrm{K}$ incr) test at $704{ }^{\circ} \mathrm{C}$ and $0.667 \mathrm{~Hz}$ at (a) low and (b) higher magnifications. Initial intergranular failure mode followed by sudden transition to mostly transgranular failure.

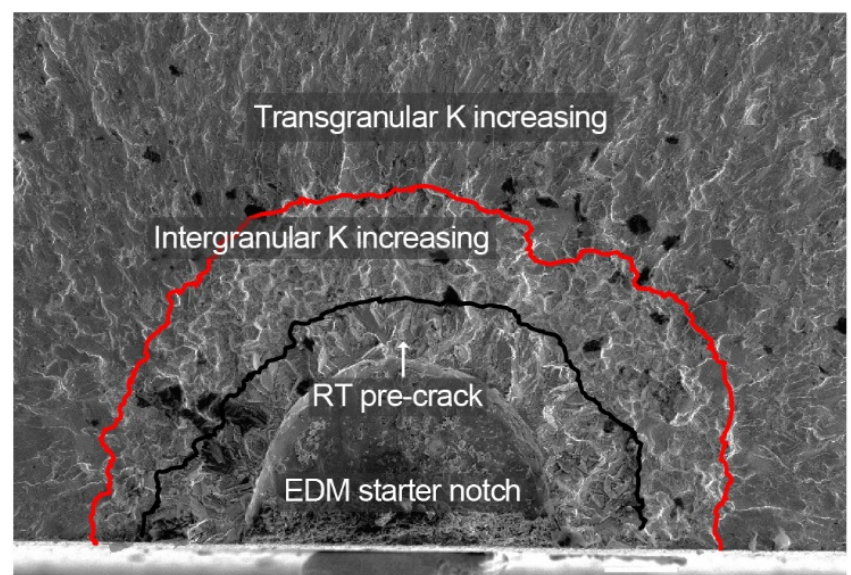

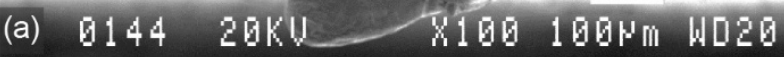

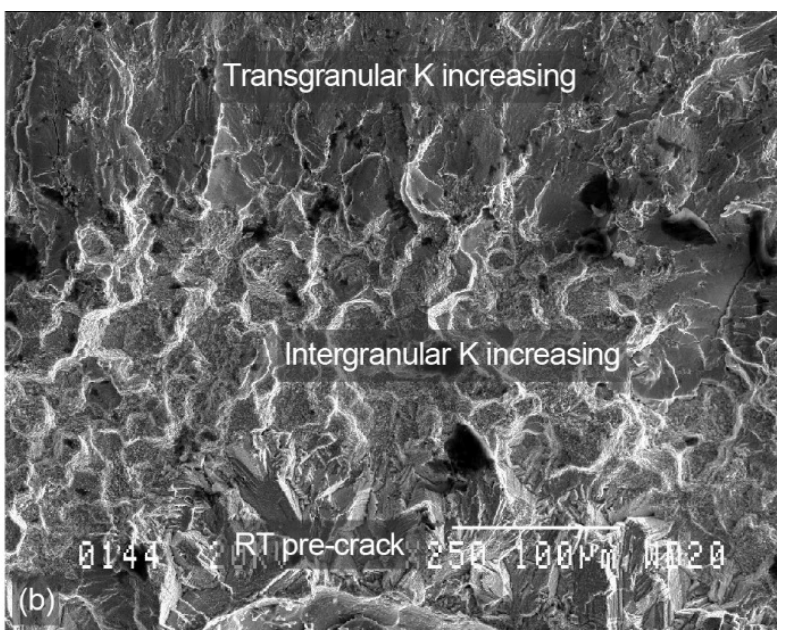

Figure 14.-LSHR short pre-crack, $\mathrm{K}$ incr. test at $704^{\circ} \mathrm{C}$ and $2.0 \mathrm{~Hz}$ at (a) low and (b) higher magnifications. An initial intergranular failure mode is followed by sudden transition to mostly transgranular failure. 
The direct relationship between the failure mode and the resulting FCG rates is shown in Figure 15 where the measured fatigue crack growth data is superimposed on top of the SEM image of the early stages of crack growth of a short pre-crack test specimen. As shown, the length of the intergranular failure mode corresponds closely to the near-threshold FCG regime measured in the test. Once the abrupt change of the failure mode occurs, a corresponding change to the slope of the FCG curve also takes place with the shallower slope indicating the onset of FCG in the Paris regime. It is important to note in Figure 15, that even in the intergranular near-threshold regime, the crack growth rates increase as a function of the crack length and thus also as a function of the applied stress intensity range. Hence, even though the crack growth mechanisms are different in the two regions, the FCG rates are still governed by the stress intensity range.

The presence of this unusual transition of the failure modes for both types of threshold tests conducted in the study, as well as the reasonable agreement between the measured near- threshold FCG rates for these two different test techniques confirms that these results are representative of a real phenomenon and are not a product of a faulty test methodology.

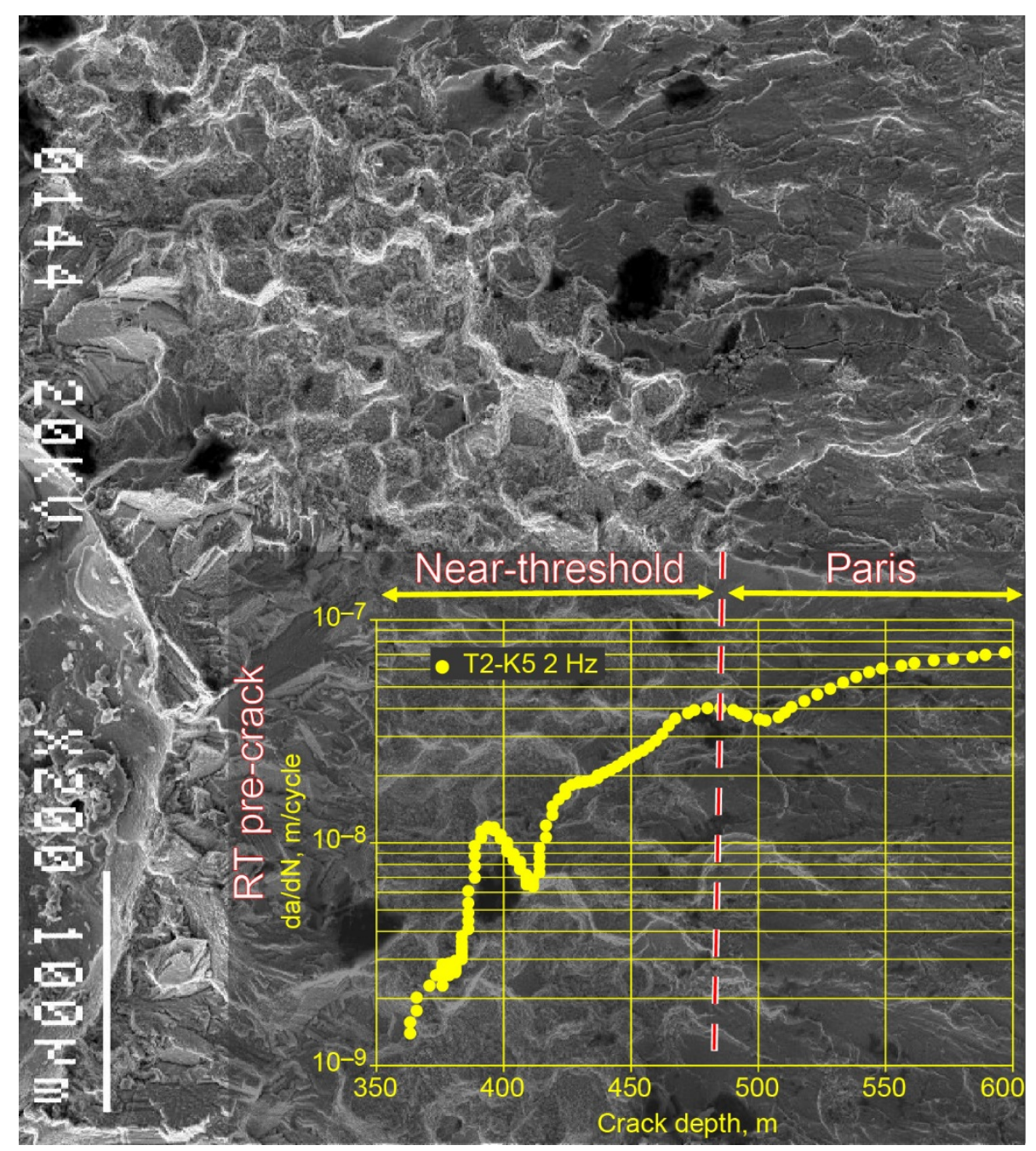

Figure 15.-LSHR short pre-crack test performed at $704^{\circ} \mathrm{C}$ and $2 \mathrm{~Hz}$. FCG rates are superimposed on the SEM fractograph. Intergranular failure mode corresponds closely with near-threshold regime. This change in failure mode is associated with the change in slope for the FCG curve in the Paris regime. 


\section{Re-initiation of Crack Growth After Completion of the Threshold FCG Test Portion}

In addition to the near-threshold short pre-crack tests described previously, $\mathrm{K}$ increasing and constant stress intensity tests were conducted on selected load shedding threshold test specimens once the desired threshold FCG rates were achieved. The K-increasing FCG results for the two ME3 specimens are shown in Figure 16 for specimens tested at 704 and $760{ }^{\circ} \mathrm{C}$. In order to get the crack growing again, it was necessary to significantly increase the stress intensity range. For example, in order to restart the crack growth for the $760{ }^{\circ} \mathrm{C}$ specimen shown in Figure 16, the $\Delta \mathrm{K}$ was increased by 5 percent increments from the threshold $\Delta \mathrm{K}$ of $14 \mathrm{MPa} \sqrt{\mathrm{m}}$. Only after finally reaching a $\Delta \mathrm{K}$ of $20.5 \mathrm{MPa} \sqrt{\mathrm{m}}$, did the crack growth commence again. Thus, in order to achieve equivalent near-threshold FCG rates considerably higher stress intensities were required for the K-increasing portion of the test at both 704 and $760{ }^{\circ} \mathrm{C}$. However, in the Paris regime (Figure 16), these differences disappear and the FCG rates from both portions of the test exhibit similar FCG rates.

The difficulty in restarting fatigue crack growth after threshold is achieved, suggests that the intergranular near-threshold crack growth region formed during threshold testing acts as a barrier which needs to be overcome in order for the crack growth to re-initiate. This barrier not only affects the restart of crack growth but also appears to slow down the near-threshold FCG rates in the K-increasing portion of the test as indicated by the arrows shown in Figure 16.

An intriguing test results from another of the ME3 load shedding test specimens provided valuable insight into the crack re-initiation process after threshold has been reached. The test was performed at $704{ }^{\circ} \mathrm{C}$ at a $0.333 \mathrm{~Hz}$ frequency. The measured load shedding FCG rates for this particular specimen were shown to be very similar to the other ME3 threshold tests (light blue circles in Figure 2). After achieving the threshold FCG rates through a previously described load shedding procedure at a $\Delta \mathrm{K}_{\text {th }}$ of $11.3 \mathrm{MPa} \sqrt{\mathrm{m}}$, an attempt was made to restart the test at a slightly higher, yet constant $\Delta \mathrm{K}$, than the measured $\Delta \mathrm{K}_{\mathrm{th}}$. The rationale for using constant $\Delta \mathrm{K}$ test methodology was to achieve significant amount of crack growth in the near-threshold FCG regime to help with interpretation of the active failure modes. Again, at the stress intensity ranges near the $\Delta \mathrm{K}_{\text {th }}$ no appreciable crack growth was achieved, so the

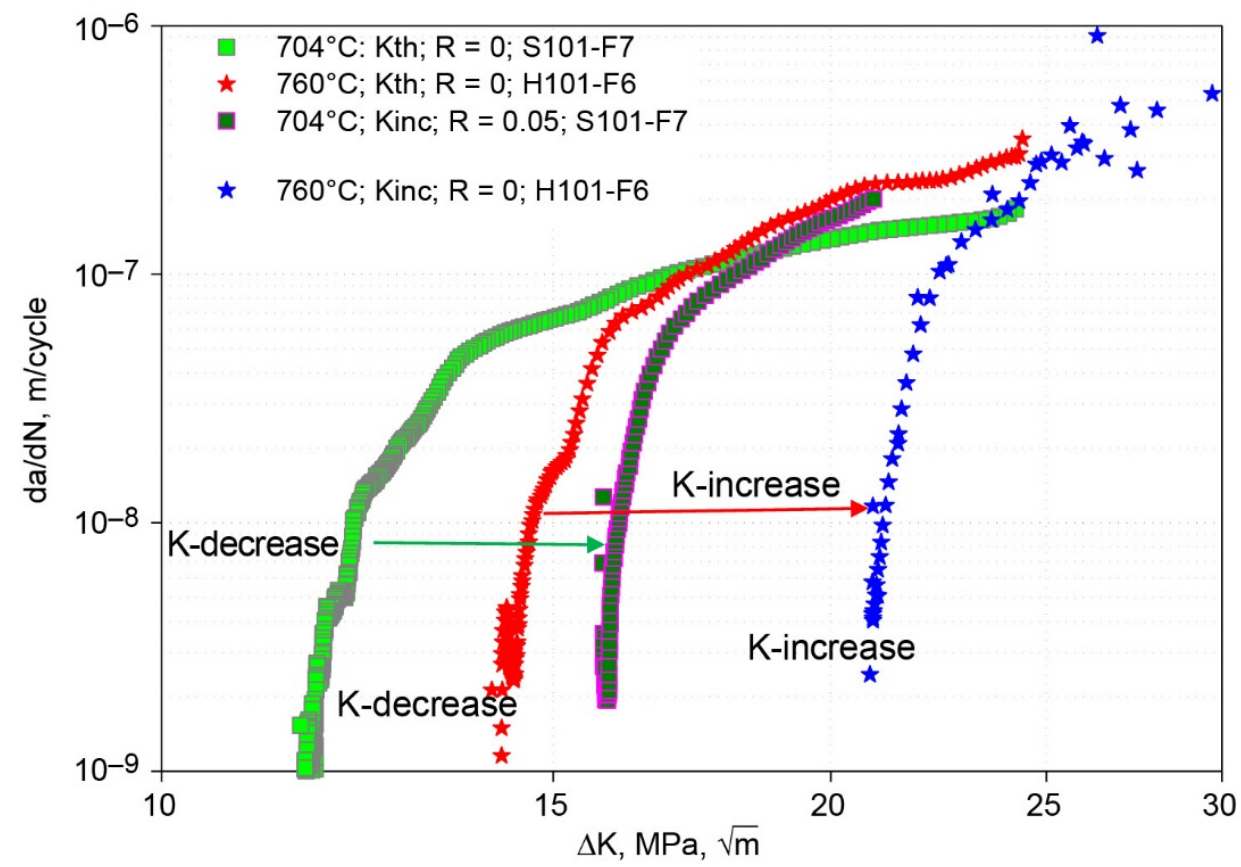

Figure 16.-ME3 tests indicated a considerable increase in applied $\Delta \mathrm{K}$ was needed to reinitiate crack growth after load shedding threshold was reached both at 704 and $760{ }^{\circ} \mathrm{C}$. 


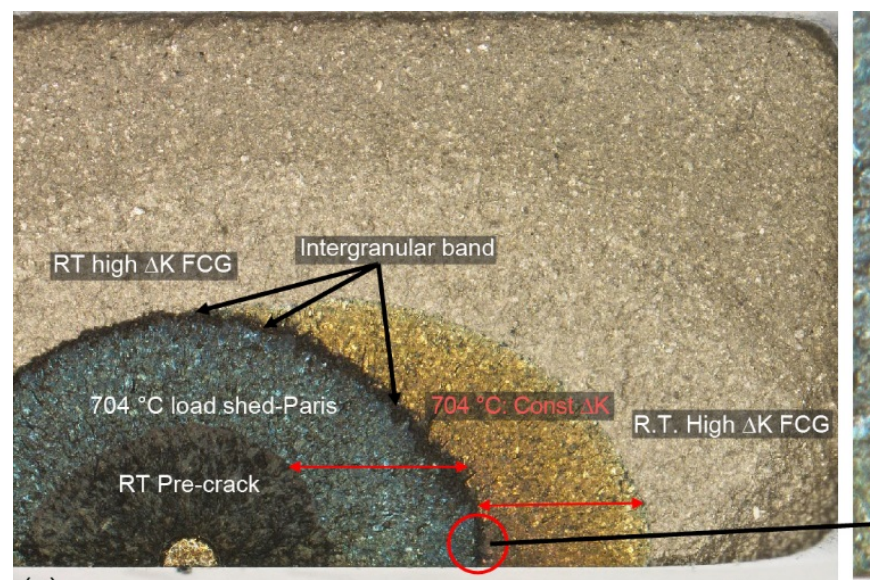

(a)

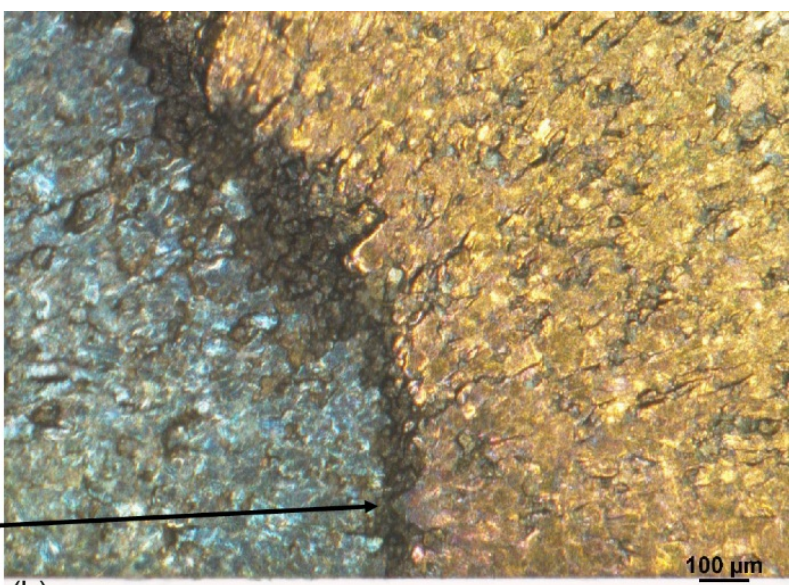

(b)

Figure 17.-ME3 fracture surface after a threshold test at $704^{\circ} \mathrm{C}$ and $0.333 \mathrm{~Hz}$. Load shedding until threshold was followed by constant $\Delta \mathrm{K}$. Constant $\Delta \mathrm{K}$ crack growth occurred only on one side of the specimen. Re-initiation of crack growth location marked by circle in (a) and shown at higher magnification in (b).

applied stress intensities were gradually increased until a constant $\Delta \mathrm{K}$ of $15 \mathrm{MPa} \sqrt{\mathrm{m}}$ was applied at which point crack growth was re-initiated. After approximately 25,000 cycles at that applied constant $\Delta \mathrm{K}$, the test was again interrupted, specimen cooled to room temperature and cycled to failure at a much higher load range than applied during the constant $\Delta \mathrm{K}$ test portion.

The post-failure macrograph of the failed specimen, Figure 17, shows that something very unusual occurred during the test. The crack growth behavior during the load shedding part of the test is very similar to others previously described, with the bluish region representing the Paris regime, consisting of mostly transgranular crack growth and the thin dark region encircling the bluish region consisting of the intergranular failure mode in the near threshold FCG regime (Figure 17(a)). Both of these regions are symmetric indicating good specimen alignment. However, on the right side of the image in Figure 17(a), past the dark region, is a golden shaded region which represents the high temperature crack growth during the constant $\Delta \mathrm{K}$ portion of the test. It is readily apparent that the "constant $\Delta \mathrm{K}$ " crack growth occurred only on one side of the specimen. Past the golden region is a light tan region which represents the room temperature crack growth segment. As evident in Figure 17(a), on the left side of the image, no high temperature post-threshold crack growth is present with the room temperature crack growth being directly adjacent to the intergranular near-threshold region. It should be noted that once this asymmetric crack growth commenced, the constant $\Delta \mathrm{K}$ conditions no longer applied since the evolution of the irregular crack shape must have had some influence on the crack driving force. However for simplicity in describing the observed post-threshold FCG behavior we will continue to refer to this regime as the "constant $\Delta \mathrm{K}$ " region.

The width of the golden-shaded, "constant $\Delta \mathrm{K}$ " crack growth region is not uniform, with the largest width being near the outside face of the specimen. The width of the "constant $\Delta K$ " region at a particular location is most likely related to the number of cycles of crack growth that occurred in that region since the re-initiation of crack growth has taken place. Based on this scenario, it would be expected that the re-initiation of crack growth first occurred in an area near the outside face of the specimen, Figure 17(b), a region with the widest width. A fractographic evaluation of that region shown in Figure 18 does indeed support this scenario. As is evident, the re-initiated crack origin of the "constant $\Delta \mathrm{K}$ " region is approximately $150 \mu \mathrm{m}$ away from the outside face of the specimen, Figure 18(a). What may be more important, is that the re-initiation occurred at the location where the intergranular near-threshold region appears to be the narrowest of the entire band encircling the specimen, Figure 18(b). This observation indirectly supports the idea that the intergranular near-threshold band acts as a barrier to cyclic crack growth through a mechanism which is not yet understood. Thus the narrower the band, the smaller is the barrier and therefore the re-initiation occurred at this particular location. 

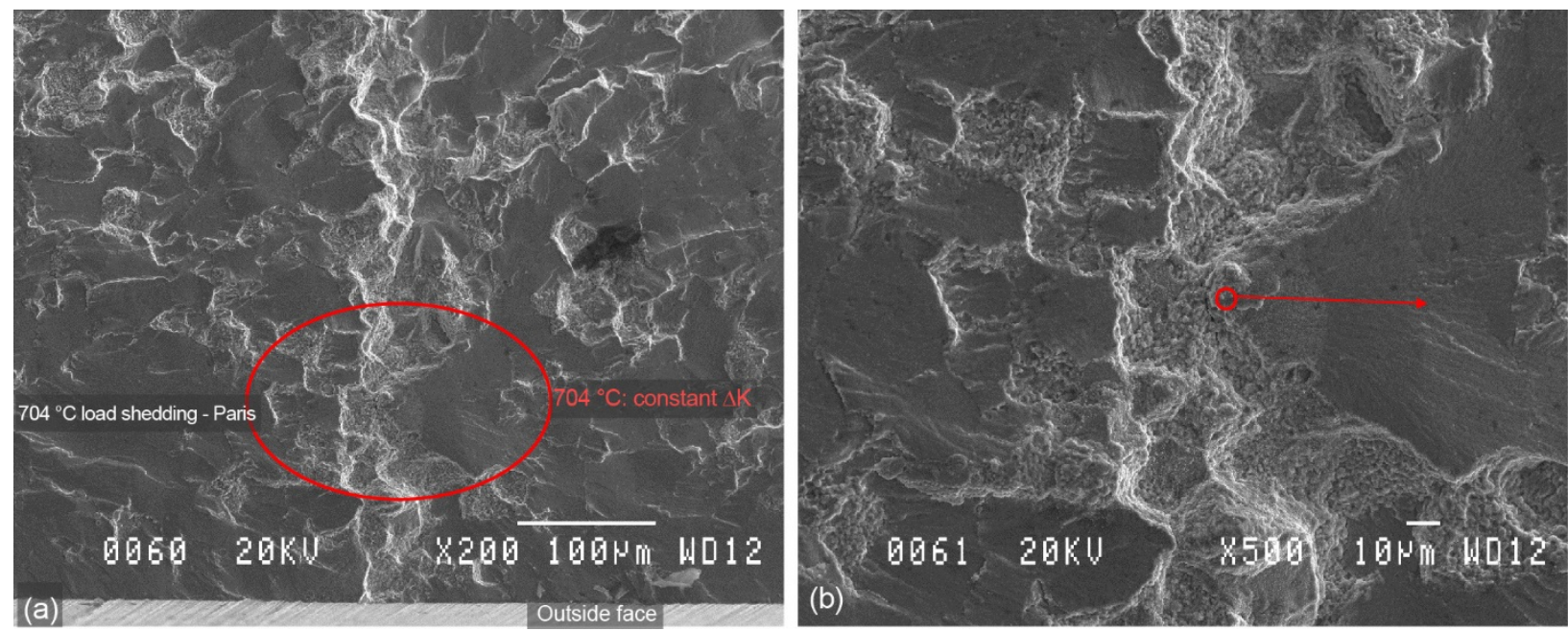

Figure 18.- Re-initiation of the mostly transgranular failure mode occurred at the narrowest point of the intergranular band, shown at: (a) low magnification and (b) higher magnification. "O" marks the re-initiation location in the "constant $\Delta \mathrm{K}$ " region.

\section{Effect of Environment and Oxide Buildup}

\section{Oxide Thickness Measurements}

The results indicate that environmental factors, especially the effect of oxidation, have a strong influence on the near-threshold cyclic FCG behavior. In order to characterize the oxides which have developed during FCG testing, an interrupted load shedding near-threshold FCG test was performed on a ME3 specimen. The purpose of this test was to identify active oxidation damage mechanisms at the crack tip by limiting the thermal exposure to prevent any additional oxidation of the crack tip area to take place. The test was performed at $704{ }^{\circ} \mathrm{C}$, at a frequency of $0.333 \mathrm{~Hz}$ and an R-ratio of 0.05 . Once the cyclic FCG rates were well within the threshold regime, approximately $2 \times 10^{-9} \mathrm{~m} /$ cycle, the test was interrupted and the furnace immediately turned off to limit the amount of time that the crack tip region was exposed to high temperature conditions. This specimen was sectioned and polished in a longitudinal section that bisected the semi-circular crack to perform high resolution microscopy. As shown in Figure 19, the measured FCG behavior of this specimen was similar to other ME3 specimens tested at the same test conditions.

Figure 20 shows the cross section of the growing crack for the interrupted specimen at various magnifications. As shown, the crack growth is mostly transgranular until the last 30 to $40 \mu \mathrm{m}$ at which point the transition to the intergranular threshold regime occurs (Figure 20(a) and (b)). High magnification image shown in Figure 20(c) reveals presence of an oxide in the crack tip region.

The oxide thickness measurements near the crack tip were performed for the interrupted ME3 test. The importance of these measurements is that they reflect the crack tip condition in the near-threshold region while the crack was still growing. This avoided the cumulative oxide buildup at the crack tip which occurs once crack growth is arrested and provided an opportunity for a more realistic oxide thickness measurements. The measurements were made using an inverted high resolution crack tip image which enhanced the contrast, Figure 21(a), with the results shown in Figure 21(b). As shown, the full crack tip oxide thickness decreases rapidly in this region, changing from approximately $300 \mathrm{~nm}$ at a distance of 5 $\mu \mathrm{m}$ from the tip to approximately $30 \mathrm{~nm}$ at a distance of 0.1 to $0.5 \mu \mathrm{m}$. 


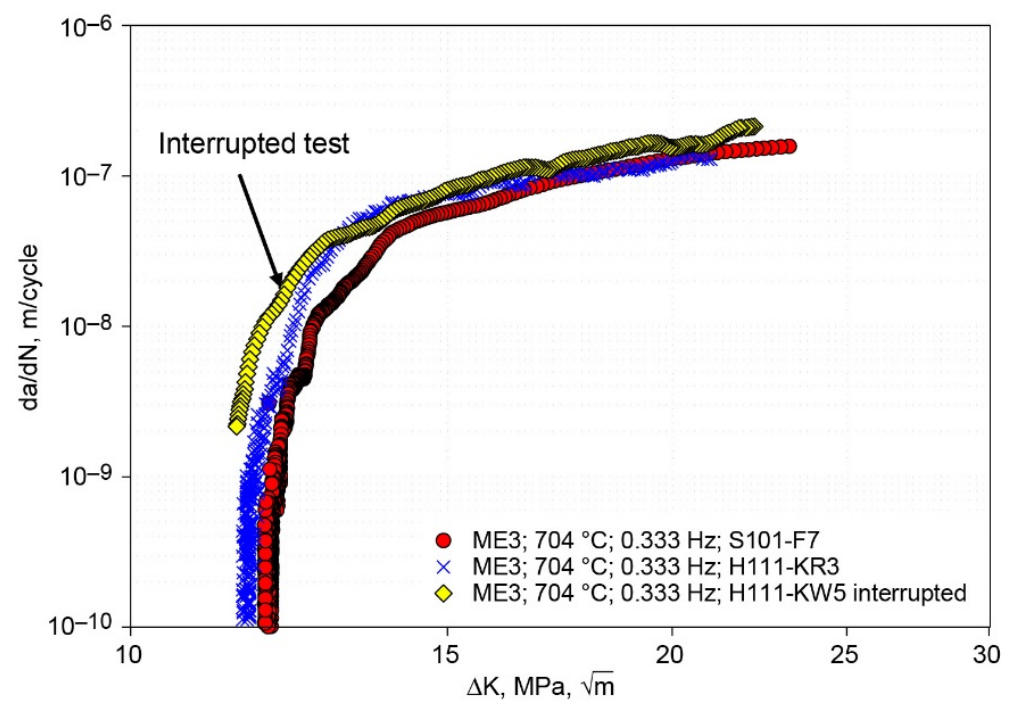

Figure 19.--The interrupted load shedding threshold test FCG behavior is in good agreement with other similar tests. The test interrupted at approximately $2 \times 10^{-9} \mathrm{~m} /$ cycle FCG rate.

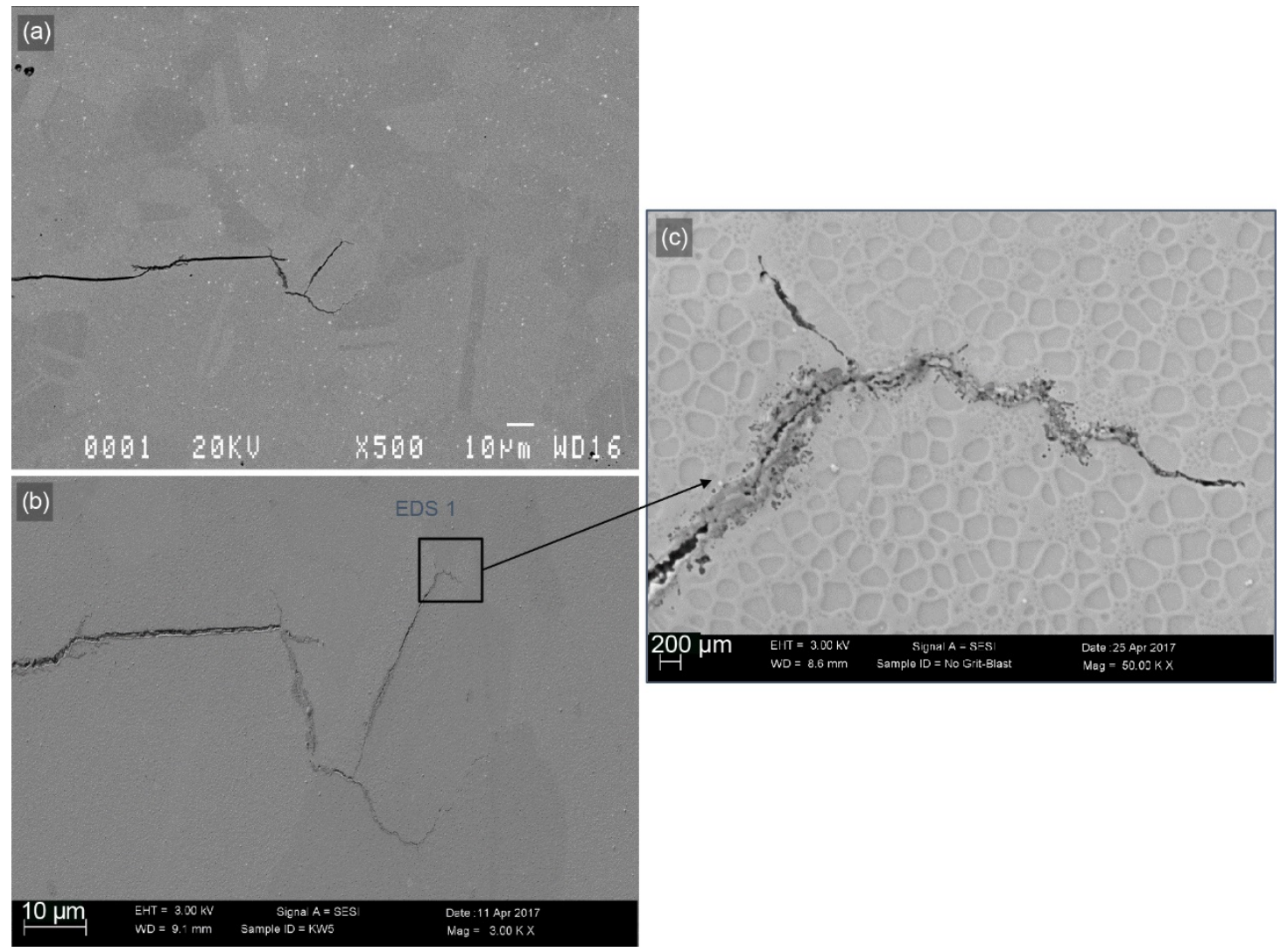

Figure 20.- SEM images taken at various magnifications of a cross section of an interrupted load shedding ME3 threshold test conducted at $704{ }^{\circ} \mathrm{C}$ and $0.333 \mathrm{~Hz}$. A sudden failure mode transition occurred within the last 30 to $40 \mu \mathrm{m}$ of the crack length. 

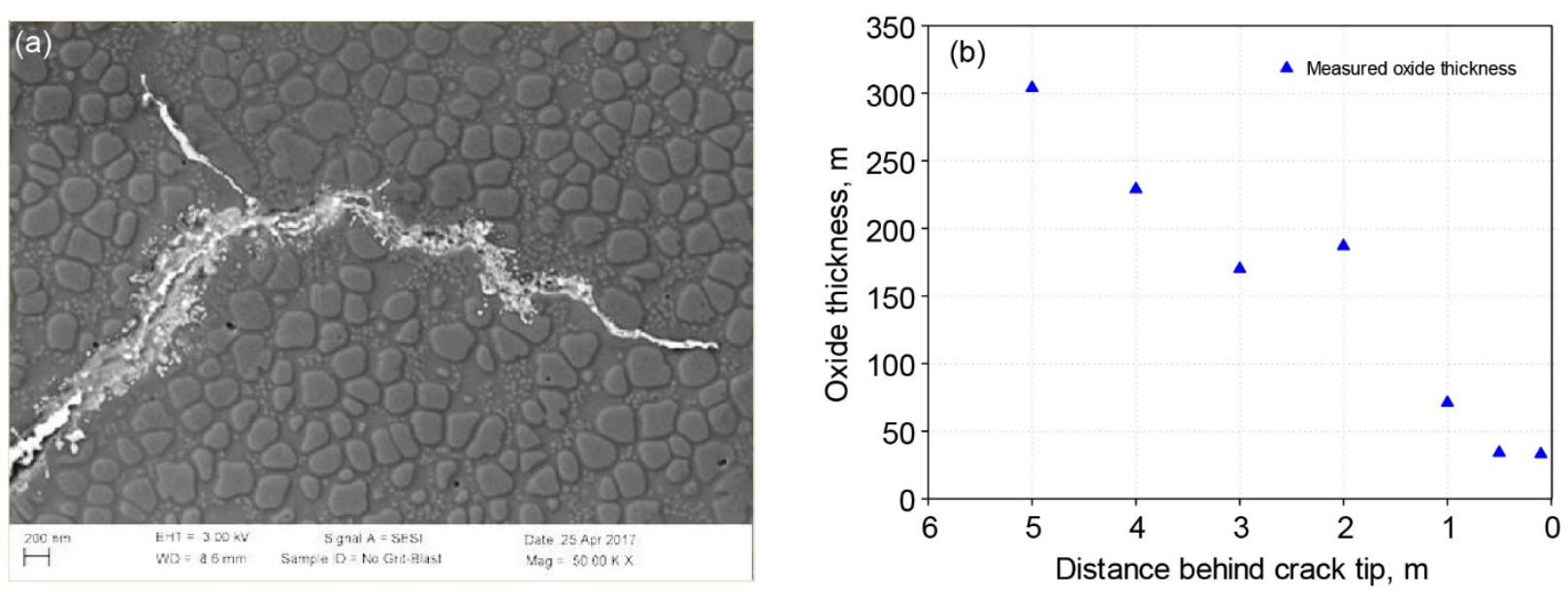

Figure 21.-Oxide thickness as a function of the distance behind the crack tip for the interrupted ME3 load shedding specimen; (a) inverted high resolution SEM image; (b) average of full oxide thickness measured from the SEM image (3 measurements per location).

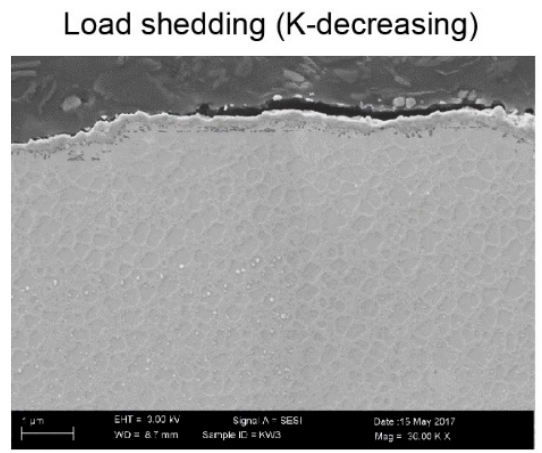

(a)

Average: $260 \mathrm{~nm}$

$95 \% \mathrm{Cl}: 34 \mathrm{~nm}$
Load shedding (near-threshold)

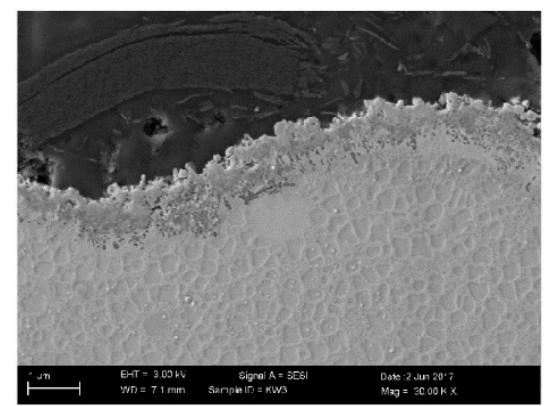

(b) Average: $636 \mathrm{~nm}$ 95\% Cl: $124 \mathrm{~nm}$
Constant-K

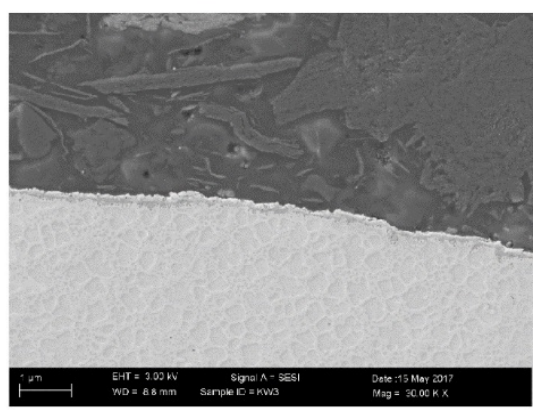

(c)

Average: $158 \mathrm{~nm}$ 95\% Cl: $18 \mathrm{~nm}$

Figure 22.--Representative images of the oxides and their measured thickness in three distinct regions of a ME3 specimen; (a) mostly transgranular, load shedding, K-decreasing segment; (b) intergranular near threshold regime; (c) constant $\mathrm{K}$ segment, mostly transgranular failure mode. Average measured oxide thickness and the 95 percent confidence interval indicated for each region (5 measurements/region).

Measurements of oxide thicknesses were also performed for another ME3 specimen at various crack length locations as a function of the test type and failure mode. The results from these measurements, obtained for a ME3 threshold specimen tested at $704{ }^{\circ} \mathrm{C}$ and $0.333 \mathrm{~Hz}$, reveal a complex relationship between the oxide buildup and the test history. The test history of this particular specimen was previously described since this was the specimen which revealed the unusual asymmetric crack growth during the "constant $\Delta \mathrm{K}$ " portion of the test (Figure 17). This specimen was sectioned parallel to the outside surface so that the cross section would encompass the asymmetrical nature of the crack front. The representative images of the oxide buildup in the mostly transgranular K-decreasing region, the intergranular nearthreshold region and the "constant $\Delta K$ " region are shown in Figure 22. The measured values represent the oxide thickness on one half of the specimen. The most striking feature of this figure is the much thicker oxide layer of approximately $630 \mathrm{~nm}$ in the intergranular near-threshold region in comparison to the $260 \mathrm{~nm}$ oxide thickness in the transgranular K-decreasing region. Since the K-decreasing test portion occurred prior to the onset of intergranular near-threshold behavior, it is clear that oxide formation is accelerated by the presence of grain boundaries in the near-threshold region. The preferential growth of oxides in the intergranular regions is most likely due to enhanced diffusion of oxygen along the grain boundaries (Ref. 15). 


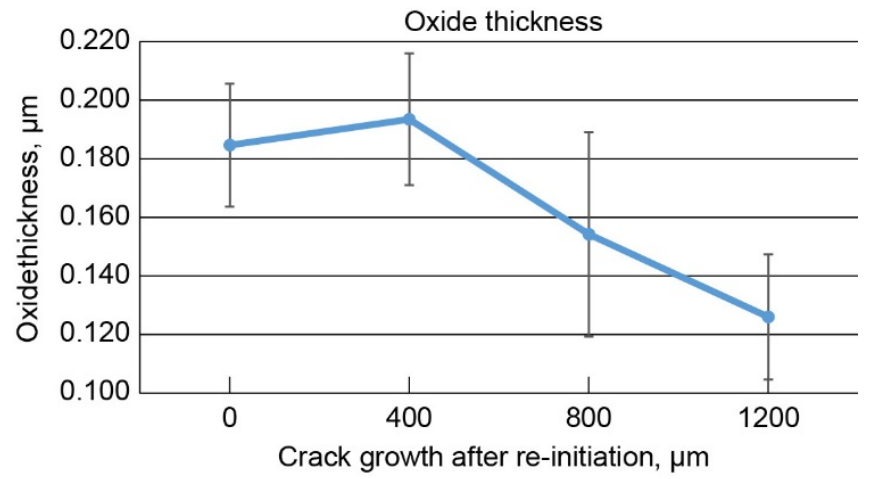

Figure 23.-Average oxide thickness in the constant $\mathrm{K}$ regime segment of the ME3 specimen as function of the distance from re-initiation of crack growth. Data brackets indicate 95 percent confidence interval.

Oxide thickness was also measured after the crack growth was re-initiated during the "constant $\Delta \mathrm{K}$ " portion of the test. As shown in Figure 23, the oxide thickness decreased gradually as a function of crack length. As described previously, due to the asymmetric crack growth behavior for this specimen in the "constant $\Delta \mathrm{K}$ " region, no FCG rates could be established for the particular locations for which the measurements were taken thus it was not possible to accurately determine the exposure time at temperature for these locations.

\section{EDS Analysis of the Oxides}

A qualitative assessment of the oxides formed at the crack tip and in the crack wake was performed on the two ME3 specimens for which oxide thicknesses were measured. Significant differences in the oxide composition were detected depending on the failure mode and exposure time. The most important comparison is between the oxide composition of the near crack tip oxides of the interrupted specimen growing in the intergranular failure mode and that of the "constant $\Delta \mathrm{K}$ " region of the other ME3 specimen which was growing by a mostly transgranular failure mode. Since these two regions represent areas which exhibit large differences in the FCG rates, the comparison of the oxides present may shed light on the underlying mechanisms. For both specimens, these locations represent the last stages of crack growth and therefore are in the regions which did not experienced excessive time at temperature.

A comparison of the elemental maps of these two areas is detailed in Figure 24. As shown, the intergranular near crack tip oxides of the interrupted specimen are rich in $\mathrm{Cr}$ and $\mathrm{Ti}$ (Figure 24(c) and (d)), while the corresponding transgranular failure region is lower in $\mathrm{Cr}$ in comparison to the surrounding alloy composition $(24 \mathrm{~g})$. The thin oxide in the transgranular failure region appears to have a higher $\mathrm{Al}$ content than the surrounding substrate, Figure 25(b). The presence of $\mathrm{Cr}$ oxides at the tip of a growing crack in the intergranular near-threshold region may be very important since $\mathrm{Cr}_{2} \mathrm{O}_{3}$ oxides are well known to inhibit environmental degradation (Ref. 16). Further discussion of the possible role that this stable oxide may play in changing the failure mode will be presented in the next section.

While $\mathrm{Cr}$ /Ti oxides predominated the crack tip of the interrupted near-threshold regime, the intergranular threshold failure region of the other ME3 specimen which was exposed to air for extensive period of time exhibited a much more complex oxide morphology. As detailed earlier, oxides grew preferentially in the region exhibiting intergranular failure (Figure 22). The additional time and temperature produced a layered structure of oxides, shown in Figure 26, with Ni rich oxides present on the outside surface, followed by discontinuous Co rich oxide particles, a thicker and almost continuous layer rich in $\mathrm{Cr}$ and containing some Ti oxides and finally a thin innermost layer rich in Al. It is likely that many of these oxides do not play a direct role in the actual intergranular near-threshold crack advancement process since they were not detected at the crack tip of the growing crack at the time that the test was interrupted. 

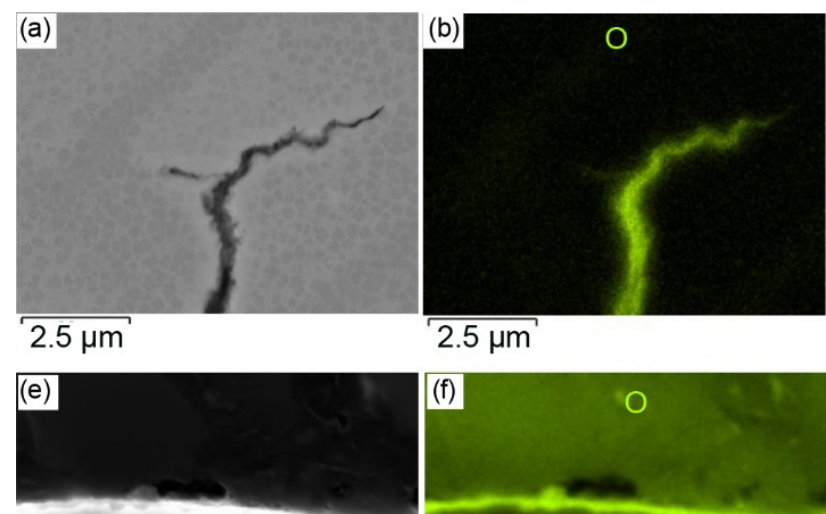
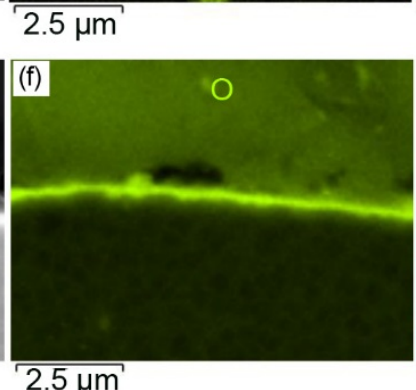

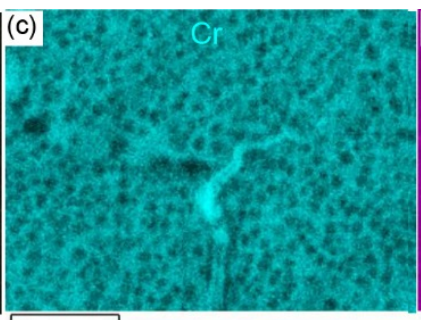

$2.5 \mu \mathrm{m}$

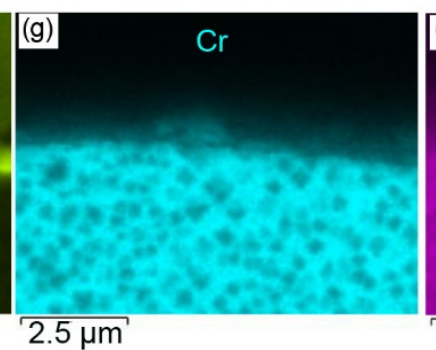

(d)

$2.5 \mu \mathrm{m}$

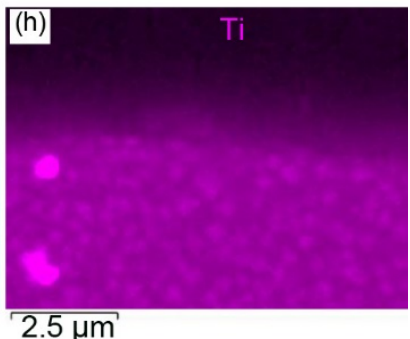

Figure 24.-ME3 interrupted test section back scatter and elemental EDS maps (a) to (d) of intergranular failure showing prevalence of $\mathrm{Cr}$ and $\mathrm{Ti}$ rich oxides at the crack tip; "constant $\Delta \mathrm{K}$ " transgranular mode EDS maps (e) to (h) show oxides leaner in $\mathrm{Cr}$ and possibly $\mathrm{Ti}$.
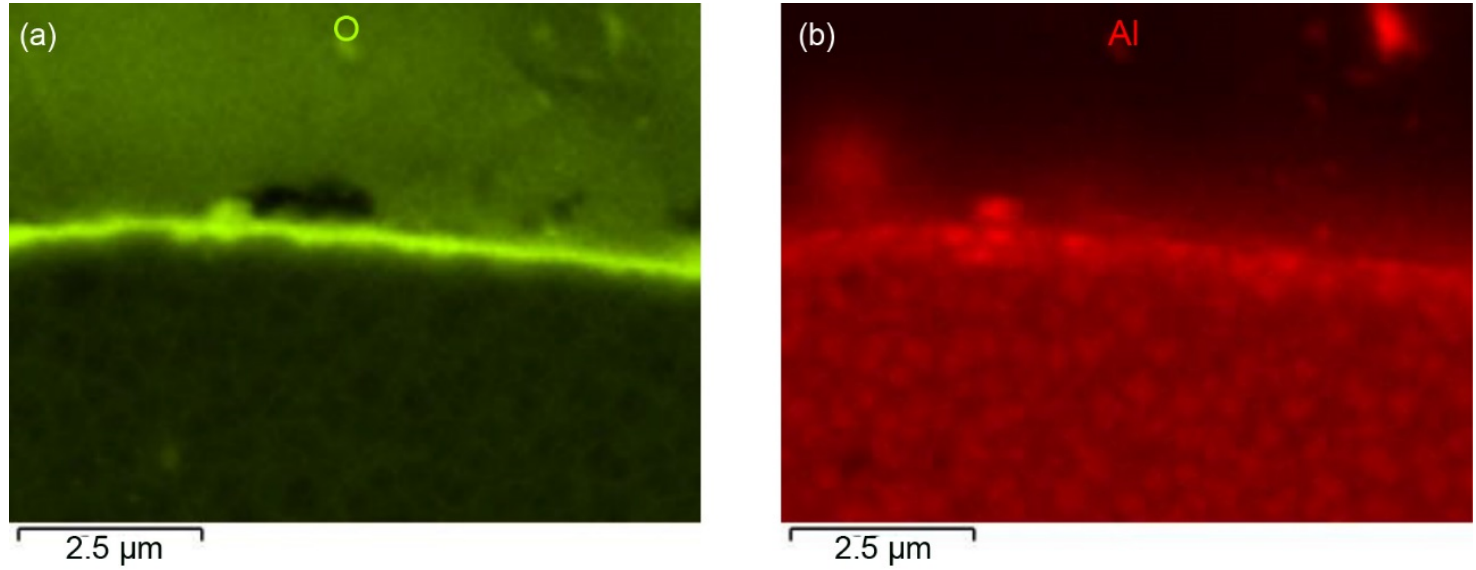

Figure 25.-EDS maps of the thin oxide layer in the "constant $\Delta K$ " ME3 test is shown in (a) The layer has a higher Al content than the substrate (b).
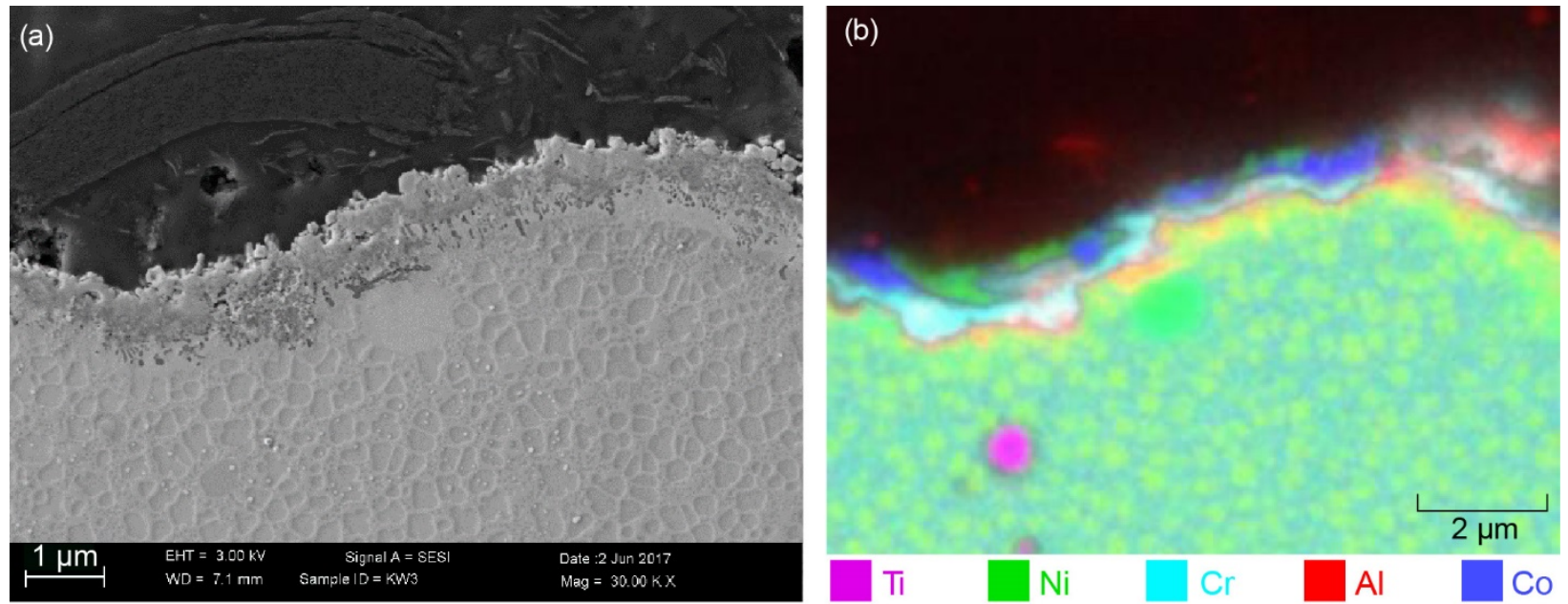

Figure 26.-ME3 intergranular surface oxide layer in the near-threshold regime shown in (a) SEM image and (b) EDS overlayed elemental map. 


\section{Discussion}

\section{Plausible Scenarios}

At this point in our research no conclusive models/mechanisms which explain all the complex observed behaviors have been fully developed. The primary objective of the paper is to describe and characterize the unusual near-threshold FCG behavior and the accompanying change in the failure mode since they have not been reported previously. However, a discussion of the observations in terms of plausible active fatigue crack growth mechanisms as well as models previously proposed to explain near-threshold FCG behavior is warranted.

The fundamental requirement for fatigue crack growth to occur is for a critical level of crack tip cyclic plasticity to take place causing back and forth motion of dislocations. The dislocation damage accumulation at the crack tip due to the dislocation motion results in crack advancement. The transition from Paris regime to near-threshold FCG rates and the accompanying sudden change in the failure modes occurs for tests conducted at $704{ }^{\circ} \mathrm{C}$ at fairly high crack growth rates $\left(\approx 4 \times 10^{-8} \mathrm{~m} /\right.$ cycle $)$. For the test conditions for which the failure mode transition did not occur (vacuum environment, lower temperature or high frequency) the threshold stress intensities were considerably lower (Figure 2 and Figure 3). These lower threshold values can be assumed to be indicative of the extrinsic $\Delta \mathrm{K}$ levels needed to reduce the crack tip plasticity to the extent that no further crack growth takes place. Thus, to explain the unusual near-threshold FCG behavior, environment-based microstructural mechanisms need to be identified which act as a barrier to crack tip plasticity and result in a sudden failure mode transition.

Two models based on the effect of oxide formation on FCG have been proposed which deal with near-threshold FCG behavior in superalloys. The well-known oxide induced closure model (Ref. 17) has been adopted by Yuen et al. (Ref. 1) to explain both the crossover effect and the higher $\Delta \mathrm{K}_{\text {th }}$ as the test temperatures are increased. The argument being that at higher temperatures, oxide thickness increases lowering the effective $\Delta \mathrm{K}$ and thus decreasing the resulting FCG rates. However this environmentally driven mechanism should not result in a failure mode transition. Further, the onset of the reduction in the crack growth rates when such mechanism is in effect should be gradual due to the time-dependent increase in the oxide thickness. However, the model may be able to explain the substantial increase in $\Delta \mathrm{K}$ needed to restart constant amplitude crack growth after threshold has been achieved using a load shedding test procedure.

A plane strain crack tip opening displacement (CTOD) can be estimated based upon the following relationship (Ref. 17):

$$
\mathrm{CTOD}=0.49\left(\frac{\Delta \mathrm{K}^{2}}{2 \mathrm{YS}^{\prime} * \mathrm{E}}\right)
$$

where YS' is the cyclic yield strength, taken to be 95 percent of the monotonic yield strength per our internal data base for these alloys, and $\mathrm{E}$ is the elastic modulus.

Based on the above equation, the calculated plane strain CTOD's at the threshold stress intensities are approximately $220 \mathrm{~nm}$ for ME3 and $250 \mathrm{~nm}$ for LSHR for tests conducted at $704{ }^{\circ} \mathrm{C}$. For the ME3 specimen, FCG was reinitiated at a $\triangle \mathrm{K}$ of $15 \mathrm{MPa} \sqrt{\mathrm{m}}$ which corresponds to a CTOD of approximately $380 \mathrm{~nm}$. As detailed previously, the oxide thickness at the crack tip of the interrupted test was approximately $30 \mathrm{~nm}$ and is thus considerably smaller than the CTOD. However, as was shown in Figure 22, the oxide layer in the intergranular threshold region of the other ME3 specimen evaluated was approximately $650 \mathrm{~nm}$ for one half of the specimen and thus is considerably larger than the calculated CTOD's. However, this value cannot be used to directly compare to the CTOD's for two reasons: (1) the value represents the total oxide thickness and not the net increase in thickness caused by volumetric expansion due to oxide formation and (2) cumulative oxide buildup in the intergranular region continued when the crack growth was reinitiated at the higher stress intensity range. However, the measurements do 
indicate that the extent of intergranular oxide buildup at crack arrest is substantial in relation to the CTOD and thus oxide-induced crack closure can at least explain a portion of the increase in $\Delta \mathrm{K}$ needed to reinitiate crack growth as well as the lower FCG rates in the near- threshold regime at a given applied $\Delta \mathrm{K}$ for the re-initiated test segments in comparison to the load shedding test portions (Figure 16).

Recently Chan has proposed a different oxide formation model (Refs. 18 and 19) which also attempts to explain the threshold behavior in superalloys. The model is based on the volumetric transformation strains produced by oxide formation which may produce large crack tip residual stresses which act to significantly reduce the crack driving force and thus shield the crack tip. He postulates that the oxide formation can induce transformation toughening at the crack tip that must be overcome for crack growth to continue through fracture of the crack tip oxide layer (Ref. 18). According to his model, oxide transformation strains produce compressive residual stresses that dominate at low stress intensities, but the magnitude and the size of the compressive stress zone decreases with increasing $\mathrm{K}$ levels and thus at higher $\Delta \mathrm{K}$ levels the contribution of the compressive stresses diminishes (Ref. 19). This is a very intriguing model which may explain some aspects of the observed threshold behavior, and deserves to be evaluated in greater detail. However, again it is difficult to see how this model could explain the sudden transition in the failure mode.

Both of these oxide models can be thought of as extrinsically-based mechanisms which reduce the effective crack driving forces and lower the near-threshold FCG rates. However, another aspect of oxide formation may also be an important player which can significantly affect near-threshold behavior.

There are two significant phenomena which will need to be explained to gain an understanding of the observed behavior. The first phenomena are the slow fatigue crack growth rates associated with intergranular failure in the near-threshold regime which are in contrast to the fast crack growth rates typically associated with intergranular failure. The second phenomena, which is more difficult to explain, are the mechanisms governing the sudden transition from mostly transgranular failure in the Paris regime to fully intergranular failure mode in the near-threshold region.

The slow, near-threshold intergranular crack growth rates may be due to the stable oxide forming at these crack growth rates. As was described earlier and shown in Figure 24, Cr-oxides were present at the intergranular crack tip of the interrupted test while the crack was still growing in the near-threshold regime. While more high resolution work is needed to confirm this result, no $\mathrm{NiO}$ were observed at these very low crack growth rates near the crack tip. A number of researchers have proposed that the formation of unstable and porous $\mathrm{NiO}$ at the crack tip significantly weakens and embrittles the grain boundaries causing fast intergranular crack growth rates (Refs. 20 to 22). Work done by Andrieu et al. (Ref. 21) and Molins et al. (Ref. 22) shows that under certain thermodynamic conditions, such as low $\mathrm{P}_{\mathrm{O} 2}$, stable $\mathrm{Cr}_{2} \mathrm{O}_{3}$ oxide film can form at the grain boundaries without prior formation of nickel oxides. The chromia oxide film is well known to act as a protective barrier from further oxidation damage in general (Ref. 16) and as was shown very convincingly by Browning (Ref. 23), it largely shields the crack tip from time depended crack growth in nickel-based superalloys.

The abundance of $\mathrm{Cr}$ and Ti oxides at the crack tip of the slow growing intergranular crack, is in contrast to the oxide layer leaner in $\mathrm{Cr}$ and higher in $\mathrm{Al}$ content of the transgranular failure mode region in the "constant $\Delta \mathrm{K}$ " regime which is associated with faster FCG rates, Figure 24 . This supports the hypothesis that the kinetic reaction times are different enough at these varying crack growth rates to produce different type of oxides. Thus, it is plausible that at the near-threshold slow crack growth rates, there is enough time for the stable $\mathrm{Cr}_{2} \mathrm{O}_{3}$ oxide to form directly at the crack tip. The protective film limits the diffusion of the embrittling species ahead of the crack tip thus limiting the crack growth rate.

As described earlier, there was a substantial difference in oxide morphology in the immediate crack tip region of the interrupted specimen in comparison to the intergranular threshold region of the "constant $\Delta \mathrm{K}$ " specimen which was exposed to high temperature for an extended time period, as shown in Figure 24 and Figure 26, respectively. The mechanisms responsible for this difference in the oxide morphology have not as yet been identified. 
The slow, intergranular FCG rates allow enough time for the oxides' thickness to increase thus further reducing the crack growth rates by decreasing the extrinsic crack driving force by a combination of the two oxide mechanisms described previously. In case of load shedding threshold tests, this process results in high extrinsic threshold $\Delta \mathrm{K}$ levels as was documented in this study. The additional oxide thickness buildup which occurs during the last stages of a threshold test, when crack growth is extremely slow or fully arrested, further decreases the extrinsic crack driving force which needs to be overcome for crack growth to resume. This mechanism results in considerably higher stress intensities required to re-initiate the crack growth during the constant load portion of the load shedding threshold tests as was demonstrated in Figure 16 and Figure 17.

In contrast as shown in Figure 12(b), the near-threshold FCG rates are similar for the short pre-crack constant load tests and the load shedding tests. This is probably due to the lack of extensive oxide buildup since the $\mathrm{K}$ increasing portion occurs immediately after the finish of the room temperature pre-cracking test segment. As shown in Figure 12 and Figure 15, the near-threshold regime intergranular failure mode was sustained even as the crack growth rates were increasing until a sudden transition to the Paris mode and mixed-mode failure occurred at a da $/ \mathrm{dN}$ of $4 \times 10^{-8} \mathrm{~m} /$ cycle.

Our review of literature has not found any models which could be readily used to explain the sudden transition of failure modes which was previously described. However, work by Mura (Ref. 24) on the effect of thin gold films on fatigue crack initiation in a carbon steel may offer a plausible explanation. His model shows that crack initiation life is increased as a function of the thickness of the inert film due to the changing elastic strain energy created by dislocations pile ups. In the context of our study, if the reaction kinetics at slow FCG rates allow for formation of the stable $\mathrm{Cr}_{2} \mathrm{O}_{3}$ film, then the associated crack tip cyclic plastic deformation can be reduced by similar mechanism as proposed by Mura. When cyclic crack tip deformation is reduced by a critical value, crack can no longer grow through plastic deformation. At this point the failure mode transition occurs. The change to an intergranular failure mode is predicated upon the grain boundaries being slightly less resistant to crack growth than the transgranular regions. Once the transition to intergranular failure occurs, the intergranular oxide models described earlier control the FCG behavior. For increasing stress intensity tests, the mechanisms are the same but the order is reversed. Once the near-threshold intergranular FCG rates are increased to a point where the reaction kinetics no longer favor the formation of a stable $\mathrm{Cr}_{2} \mathrm{O}_{3}$ crack tip oxide, cyclic plasticity is increased and the typical fatigue crack growth behavior becomes predominant.

This scenario also explains the lack of failure mode transitions and lower threshold stress intensities in tests conducted in vacuum, lower temperatures or high frequencies. Under all these conditions the kinetics do not allow for formation of stable crack tip oxide and thus the magnitude of crack tip plastic deformation is large enough to allow for continuation of fatigue crack growth until threshold is reached.

These scenarios are offered as a starting point for further research into this interesting behavior. Much research remains to be performed to quantify, characterize and model the near- threshold behavior of this class of alloys. This research could be particularly important for achieving accurate damage tolerance life predictions of the threshold fatigue crack growth behavior under both cyclic and hold time conditions, which consumes the bulk of the crack growth lives.

\section{Conclusions}

The paper analyzes the near-threshold fatigue crack growth behavior of two nickel-based disk superalloys. The focus of the study was the unusual crossover effect in the near-threshold region of these type of alloys where the conditions which produce higher crack growth rates in the Paris regime can also produce higher resistance to crack growth in the near-threshold regime.

1. It was shown that this unusual near-threshold behavior is directly associated with a sudden, unexpected change in the fatigue failure mode from a predominantly transgranular mode in the Paris regime to a fully intergranular mode in the threshold fatigue crack growth region. This sudden transition of failure modes in the near-threshold regime has not been previously reported. The change 
to the intergranular failure in the slow crack growth near-threshold regime is unexpected, since this type of failure mode is typically associated with fast FCG rates.

2. No change in failure mode was observed for FCG threshold tests performed in vacuum, or in high frequency tests conducted in air or at lower temperatures. This signifies that the failure mode transition process is driven by environmental interactions at the crack tip.

3. The threshold FCG tests which exhibited the sudden failure mode change resulted in 25 to 30 percent higher threshold $\Delta \mathrm{K}$ levels and substantially lower FCG rates than the tests which did not exhibit failure mode transition and the crossover effect. The near-threshold intergranular failure mode was observed at crack growth rates below $4 \times 10^{-8} \mathrm{~m} /$ cycle and encompassed intergranular region band widths anywhere from 70 to $220 \mu \mathrm{m}$ which depended on the alloy and test conditions.

4. Cr and Ti rich oxides were identified at the crack tip of an interrupted test in the near- threshold regime of an intergranular crack. In contrast, for a crack growing through a transgranular failure mode, the oxides were leaner in $\mathrm{Cr}$ and richer in $\mathrm{Al}$ suggesting that the reaction kinetics play an important role in determining the failure mechanisms.

5. While no definitive explanation for this behavior has as yet been developed, it was proposed that formation of stable $\mathrm{Cr}_{2} \mathrm{O}_{3}$ oxide at slow crack growth rates blocks further environmental degradation and provides a barrier for cyclic plastic damage accumulation. Once the plastic crack tip deformation is reduced below a critical level, the change to an intergranular failure mode is predicated upon the grain boundaries being slightly less resistant to crack growth than the transgranular regions. The slow near-threshold intergranular FCG rates are also influenced by oxide-induced crack closure and the oxide volume transformation induced compressive residual stresses.

\section{References}

1. J.L. Yuen, P. Roy and W.D. Nix, Effect of Oxidation Kinetics on the Near Threshold Fatigue Crack Growth Behavior of a Nickel Base Superalloy, Met. Trans. A, Vol. 15A, Sept. 1984, 1769-1775.

2. M.A. Hicks and J.E. King, Temperature effects on fatigue thresholds and structure sensitive crack growth in a nickel-base superalloy, Int. J. of Fatigue, Vol 5, No 2, April 1983, 67-74.

3. A. Shyam, S. Padula, S. Marras and W. Milligan, Fatigue Crack Growth Thresholds in a Nickel-Base Superalloy at High Frequencies and Temperatures, Met. and Matls. Trans. A, Vol 33A, July 2002, 1949-1962.

4. S. Padula, The Fatigue Crack Propagation Behavior of a Polycrystalline Nickel-Base Superalloy in the Near Threshold Regime, PhD Thesis, Michigan Technology University, 2002.

5. H.Y. Li, J.F. Sun, M.C. Hardy, H.E. Evans, S.J. Williams, T.J.A. Doel and P. Bowen, Effects of microstructure on high temperature dwell fatigue crack growth in a coarse grain PM nickel based superalloy, Acta Mat. 90, 2015, 355-369.

6. J.E. King, Fatigue crack propagation in nickel-base superalloys - effects of microstructure, load ratio, and temperature, Materials Science and Technology, Vol 3, 1987, 750-764.

7. R.M. Wallace, C.G. Annis and D.L. Sims, Application of Fracture Mechanics at Elevated Temperatures, AFML-TR-76-176 Part II, April 1977.

8. T.P. Gabb, J. Telesman, P.T. Kantzos, K. O'Connor, Characterization of the Temperature Capabilities of Advanced Disk Alloy ME3, NASA/TM-2002-211796, 2011.

9. T.P. Gabb, J. Telesman, P.T. Kantzos, A. Garg, Effects of Temperature on Failure Mode for a Nickel-Base Disk Superalloy, J. Fail. Analysis and Prevention, 7, 2007, 56-65.

10. K. Makhlouf and J.W. Jones, Near-threshold fatigue crack growth behaviour of a ferritic stainless steel at elevated temperatures, Int. J. Fatigue, 14, No 2, 1992, 97-104.

11. J.C. Chesnutt and J.A. Wert, Effect of Microstructure and Load Ratio on $\Delta \mathrm{K}_{\text {th }}$ in Titanium Alloys, Proc. of the International Symposium on Fatigue Crack Growth Threshold Concepts, eds D. Davidson and S. Suresh, Philadelphia, Pa, TMS, 1984, 83-97. 
12. A.K. Vasudevan and P.E. Bretz, Near-Threshold Fatigue Crack Growth Behavior of 7XXX and 2XXX Alloys: A Brief Review, Proc. of the International Symposium on Fatigue Crack Growth Threshold Concepts, eds D. Davidson and S. Suresh, Philadelphia, Pa, TMS, 1984, 25-42.

13. J.A. Newman, The Effects of Load Ratio on Threshold Fatigue Crack Growth of Aluminum Alloys, PhD Thesis, Virginia Tech, 2000.

14. ASTM E647-15e, Standard Test Method for Measurement of Fatigue Crack Growth Rates, ASTM International, West Conshohocken, PA, 2015.

15. J.C. Fisher, Calculation of Diffusion Penetration Curves for Surface and Grain Boundary Diffusion, J. of Applied Physics, Vol 22, No. 1, 1951, 74-77.

16. N. Birks, G.H. Meier, and F.S. Pettit, Introduction To The High-Temperature Oxidation of Metals, $2^{\text {nd }}$ Eds.,Cambridge University Press, 2006.

17. S. Suresh, G.F. Zamiski and R.O. Ritchie, Oxide-Induced Crack Closure: An Explanation for Near-Threshold Corrosion Fatigue Crack Growth Behavior, Met. Trans. A, Vol 12A, August 1981, $1435-1443$.

18. K.S. Chan, Time-Dependent Crack Growth Thresholds of Ni-Base Superalloys, Metallurgical and Materials Transactions A, Vol 45, Issue 8, 2014, 3454-3466.

19. K.S. Chan, Mechanistic modelling of time-dependent fatigue crack growth in Ni-based superalloys, Materials at High Temperatures, Vol 33, No 4 and 5, 2016, 425-438.

20. L. Viskari, M. Hornqvist, K.L. Moore, Y. Cao, K. Stiller, Intergranular crack tip oxidation in a Ni-base superalloy, Acta Materialia, Vol 61, Iss. 10, 2013, 3630-3639.

21. E. Andrieu, G. Hochstetter, R. Molins and A. Pineau, Oxidation Mechanisms in Relation to High Temperature Fatigue Crack Growth Properties of Alloy 718, Proc of Superalloys 718, 625, 706 and Various Derivatives, Edited by E.A. Loria, TMS, 1994, 619-631.

22. R. Molins, J.C. Chassaigne and E. Andrieu, Nickel Based Alloy Intergranular Embrittlement in Relation with Oxidation Mechanisms, Materials Science Forum, Vols. 251-254, 1997, 445-452.

23. P.F. Browning, Time Dependent Crack Tip Phenomena in Gas Turbine Disk Engines, PhD Thesis, Rensselaer Polytechnic Institute, 1998.

24. T. Mura, A theory of fatigue crack initiation, Matls. Science and Eng. A, 176, 1994, 61-70. 


